Prepared in cooperation with the Socioeconomic Benefits Community

A workshop organized by the National Aeronautics and Space Administration, the U.S. Geological Survey, the University of Colorado, Boulder, and the George Washington University, Elliott School of International Affairs

\title{
Assessing the Socioeconomic Impact and Value of Open Geospatial Information
}

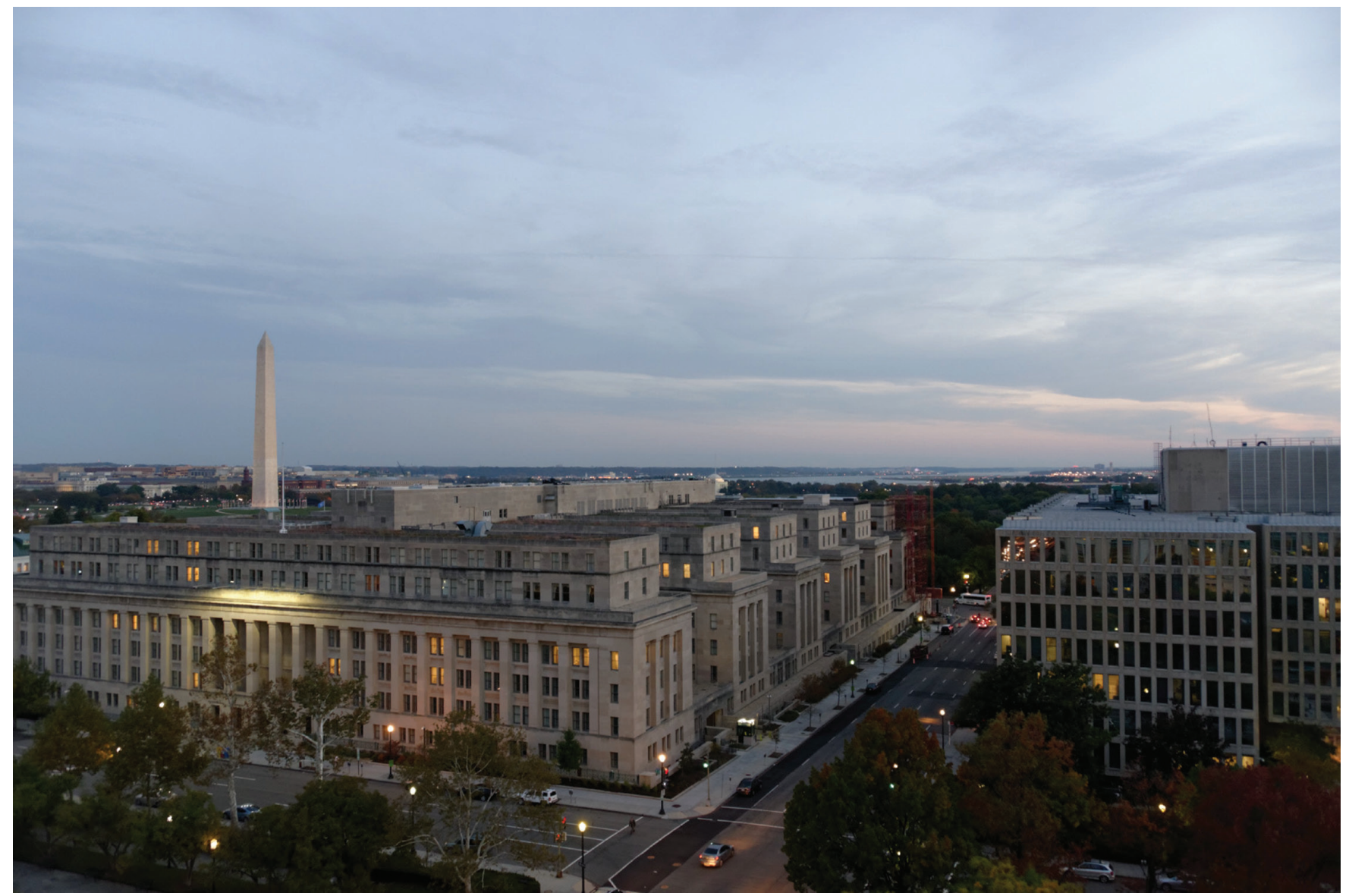

Open-File Report 2016-1036

U.S. Department of the Interior

U.S. Geological Survey 
Cover: A view of the Washington, D.C. skyline from the workshop. 
A workshop organized by the National Aeronautics and Space Administration, the U.S. Geological Survey, the University of Colorado, Boulder, and the George Washington University, Elliott School of International Affairs

\section{Assessing the Socioeconomic Impact and Value of Open Geospatial Information}

By Francoise Pearlman, Jay Pearlman, Richard Bernknopf, Andrew Coote, Massimo Craglia, Lawrence Friedl, Jason Gallo, Henry Hertzfeld, Claire Jolly, Molly Macauley, Carl Shapiro, and Alan Smart

Prepared in cooperation with the Socioeconomic Benefits Community

Open-File Report 2016-1036 


\title{
U.S. Department of the Interior SALLY JEWELL, Secretary
}

\section{U.S. Geological Survey Suzette M. Kimball, Director}

\author{
U.S. Geological Survey, Reston, Virginia: 2016
}

For more information on the USGS - the Federal source for science about the Earth, its natural and living resources, natural hazards, and the environment—visit http://www.usgs.gov or call 1-888-ASK-USGS.

For an overview of USGS information products, including maps, imagery, and publications, visit http://www.usgs.gov/pubprod/.

Any use of trade, firm, or product names is for descriptive purposes only and does not imply endorsement by the U.S. Government.

Although this information product, for the most part, is in the public domain, it also may contain copyrighted materials as noted in the text. Permission to reproduce copyrighted items must be secured from the copyright owner.

Suggested citation:

Pearlman, Francoise, Pearlman, Jay, Bernknopf, Richard, Coote, Andrew, Craglia, Massimo, Friedl, Lawrence, Gallo, Jason, Hertzfeld, Henry, Jolly, Claire, Macauley, Molly, Shapiro, Carl, and Smart, Alan, 2016, Assessing the socioeconomic impact and value of open geospatial information: U.S. Geological Survey Open-File Report 2016-1036, 36 p., http://dx.doi.org/10.3133/ofr20161036.

ISSN 2331-1258 (online) 


\section{Acknowledgments}

The organizations and agencies listed below are acknowledged for providing financial, organizational, and (or) logistical cosponsorship of the workshop:

- National Aeronautics and Space Administration (NASA)

- U.S. Geological Survey (USGS)

- University of Colorado, Boulder (CU)

- IEEE-USA

- The Space Policy Institute

- Elliott School of International Affairs, George Washington University

The organizers would like to thank NASA for their funding under grant NNX14001G, USGS for their funding under grant G14AC00303 to the University of Colorado (CU), CU and IEEE-USA for contributing financial support and George Washington University Elliott School of International Affairs for providing the workshop venue and logistics support.

The authors would like to thank Nancy Serby from NASA, Sophia Liu from the USGS, and the students from the Elliott School of International Affairs for sharing their notes of the workshop. Appreciation is also given to Shonte Jenkins from the USGS for her excellent production efforts in developing an early draft. Special thanks are given to Michael Deacon of the USGS for his exceptional editorial review within a tight deadline.

This report summarizes discussion at the Workshop on Assessing the Impact and Value of Open Geospatial Information held at George Washington University in Washington, D.C. in October 2014. This event was cosponsored by the USGS, NASA, CU, IEEE-USA, the Space Policy Institute, and George Washington University. Comments made by speakers not affiliated with the USGS do not represent the views or position of the USGS. Any opinions, findings, and conclusions or recommendations expressed in this material are those of the authors and do not necessarily reflect the views of NASA, CU, or IEEE. 


\section{Contents}

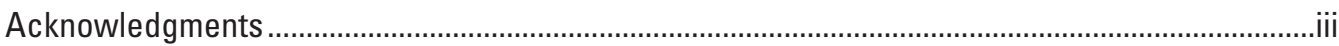

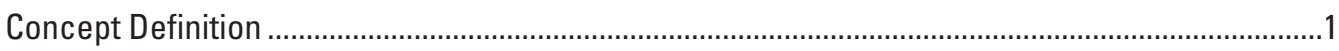

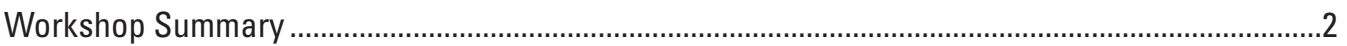

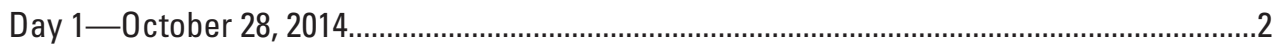

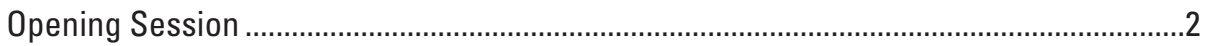

Keynote-Open Geospatial Information: Empowering Decisions and the

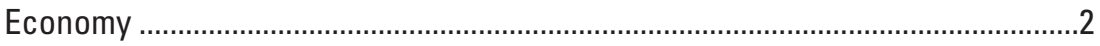

Keynote-The Emerging Information Environment and Impacts on

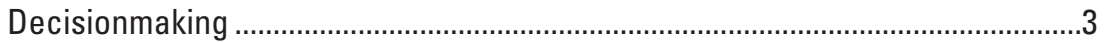

Keynote-Future Evolution of Geospatial Information Sector...........................................

Session 1. Impact of Increased Access to Data and New Modes of Consumption .5

Session 2. Increased Supply of Geospatial Information and Expanded Participatory Processes in the Production of Data ..............................................10

Perspectives_A Dialogue Between Panelists .............................................................12

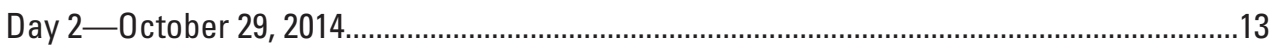

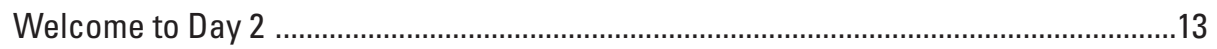

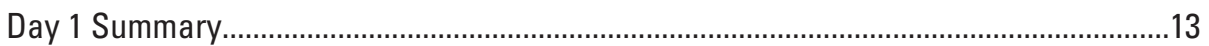

Keynote-Social Impact of Information Abundance ..................................................14

An Interactive Discussion on Data Impacts on Decisionmaking ...................................15

Session 3. Emerging Approaches for Economic Impact Assessments .......................15

Session 4. Emerging Issues for Societal Impact Assessments..................................18

Workshop Recommendations and Summary .................................................................20

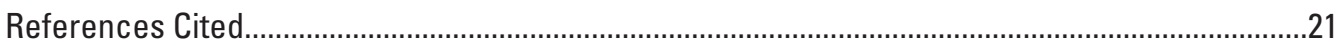

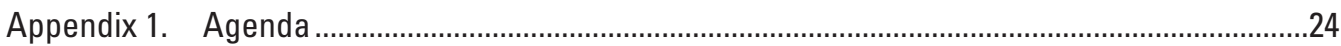

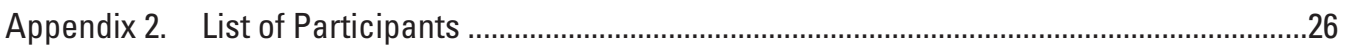

Appendix 3. Brief Biography of the Speakers, Session Chairs, and Discussants .........................28

\section{Figures}

1. Workshop attendees listen to presentations.

2. Suzette Kimball, U.S. Geological Survey Acting Director, opens the workshop................2

3. Nick Sinai, U.S. Deputy Chief Technology Officer, Office of Science and Technology Policy.

4. Walter Scott, founder of DigitalGlobe, focuses on the future of geospatial information.

5. Session 1 panel

6. John Houghton presents a paper on the impacts of increased access and new modes of consumption.

7. Diagram showing the range of approaches for considering societal benefits ................7

8. Graph showing movement from traditional notions of science to science with uncertain facts, disputed values, high stakes, and urgent decisions...............................

9. Session 2 panel 
10. Max Craglia presents a paper he developed in collaboration with Lea Shanley ............10

11. Perspectives for the workshop panelists ......................................................................12

12. Lawrence Friedl gives his perspectives on the first day of the workshop ......................13

13. Myron Gutmann gives a keynote address on the impact of information abundance . .15

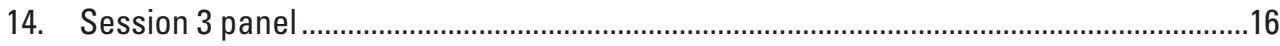

15. Richard Bernknopf presents the position paper on emerging approaches to economic assessment developed in collaboration with Carl Shapiro ..............................16

16. Session 4 panel discusses the changing role of data in society.......................................18

17. Bridgette Wessels presents the position paper on emerging issues for societal

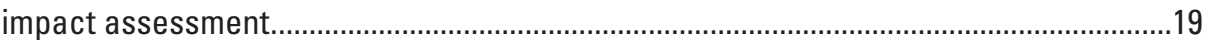

18. Jamie Kruse draws lessons learned from the workshop ...................................................20

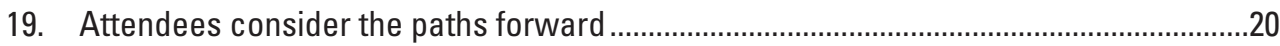




\section{Abbreviations}

\begin{tabular}{ll} 
API & application program interface \\
CMS & Center for Medical Services \\
EO & Earth Observation \\
EC-JRC & European Commission-Joint Research Centre \\
EPA & U.S. Environmental Protection Agency \\
ESIP & Earth Sciences Information Partnership \\
FEMA & Federal Emergency Management Agency \\
GDP & gross domestic product \\
GLAM & galleries, libraries, archives, and museums \\
GMO & genetically modified organism \\
GPS & global positioning system \\
IT & information technology \\
lidar & light detection and ranging \\
LSST & Large Synoptic Survey Telescope \\
MRLI & moderate resolution land imagery \\
NGO & nongovernmental organization \\
NOAA & National Oceanic and Atmospheric Administration \\
NSF & National Science Foundation \\
NYU & New York University \\
OECD & Organisation for Economic Co-operation and Development \\
OSTP & Office of Science and Technology Policy \\
PSI & public sector information \\
Rol & return on investment \\
OA/OC & quality assurance/quality control \\
UAV & unmanned aerial vehicle \\
USAID & U.S. Agency for International Development \\
USGS & U.S. Geological Survey \\
VOI & value of information \\
\hline
\end{tabular}




\title{
Assessing the Socioeconomic Impact and Value of Open Geospatial Information
}

\author{
By Francoise Pearlman, ${ }^{1}$ Jay Pearlman, ${ }^{1}$ Richard Bernknopf, ${ }^{2}$ Andrew Coote ${ }^{3}$ Massimo Craglia ${ }^{4}$ \\ Lawrence Friedl, ${ }^{5}$ Jason Gallo, ${ }^{6}$ Henry Hertzfeld, ${ }^{7}$ Claire Jolly, ${ }^{8}$ Molly Macauley, ${ }^{9}$ Carl Shapiro, ${ }^{10}$ and \\ Alan Smart ${ }^{11}$
}

\section{Concept Definition}

The production and accessibility of geospatial information including Earth observation is changing greatly both technically and in terms of human participation. Advances in technology have changed the way that geospatial data are produced and accessed, resulting in more efficient processes and greater accessibility than ever before. Improved technology has also created opportunities for increased participation in the gathering and interpretation of data through crowdsourcing and citizen science efforts. Increased accessibility has resulted in greater participation in the use of data as prices for Government-produced data have fallen and barriers to access have been reduced.

The increase in participation in the production and in the use of data, defined as data democracy for this workshop, are having great impacts on economics and more generally on society.

There is also a strong drive by governments around the world, as shown by the G8 Declaration in June 2013 (Cabinet Office, 2013), to make public sector information and scientific data more widely accessible. These are respectively termed "open data" and "open research data."

The workshop participants examined the consequences of expanding data democracy with a focus on its socioeconomic impacts. Evaluations were presented of state-of-the-art methods to assess these socioeconomic impacts, which included position

\footnotetext{
${ }^{1} \mathrm{~J} \& \mathrm{~F}$ Enterprise.

${ }^{2}$ University of New Mexico.

${ }^{3}$ ConsultingWhere, U.K.

${ }^{4}$ European Commission-Joint Research Centre.

${ }^{5}$ National Aeronautics and Space Administration.

${ }^{6}$ Science and Technology Policy Institute.

${ }^{7}$ George Washington University.

${ }^{8}$ Organization for Economic Co-operation and Development.

${ }^{9}$ Resources for the Future.

${ }^{10}$ U.S. Geological Survey.

${ }^{11}$ ACIL Allen Consulting.
}

papers and remarks by discussants. The workshop included discussions about the following topics:

- Increased and expanded information sources.

- Societal impacts, including approaches to economic assessments.

- Constraints to open access, including the demands for return on investment, specifications of intellectual property rights, and privacy issues.

- Learning from WHexperiences of other data-rich, domains, such as environmental management, internet businesses, health, and transportation.

The workshop was a working meeting with strong participant engagement, leading to recommendations for action. The meeting included five topic-driven sessions and keynote presentations (appendix 1). Precirculated position papers for each panel session facilitated preparation and remarks by discussants. After the position papers are updated following the discussants' remarks, it is planned to submit them for publication.

The workshop included 68 participants coming from international organizations, the U.S. public and private sectors, nongovernmental organizations, and academia (fig. 1).

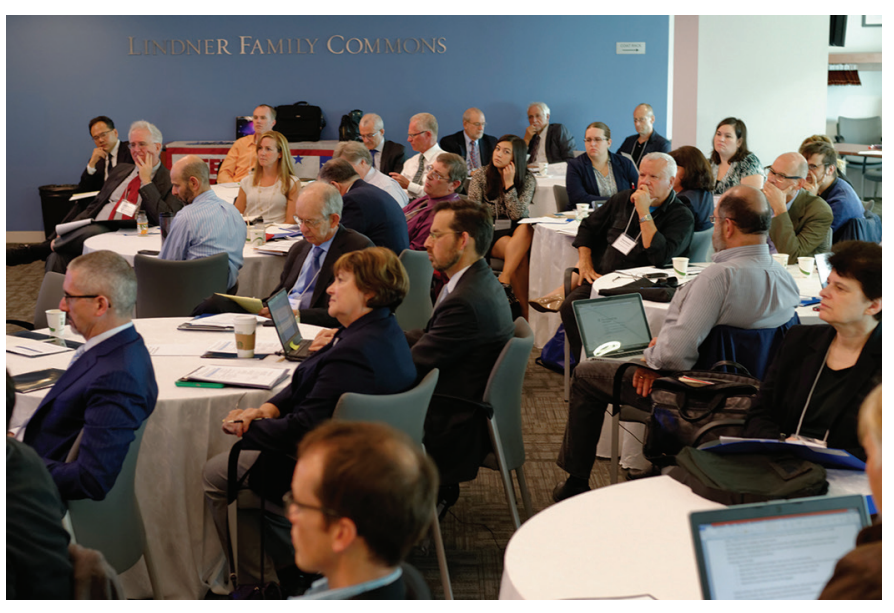

Figure 1. Workshop attendees listen to presentations. 
Participants included policy makers and analysts, financial analysts, economists, information scientists, geospatial practitioners, and other discipline experts. A list of participants is included in appendix 2. A brief biography of the speakers, session chairs, and discussants is provided in appendix 3 .

\section{Workshop Summary}

\section{Day 1-0ctober 28, 2014}

\section{Opening Session}

Molly Macauley, Resources for the Future (RFF)

As co-chair of the workshop, Molly opened the session. In her opening remarks, she referred to a Wall Street Journal article titled, "The Big Mystery—What's Big Data Really Worth?" (Monga, 2014), indicating, "You cannot manage what you do not measure." Measurement of the socioeconomic benefit and its value of geospatial information are critical inputs for society to weigh in its deliberation of the future of spatial data and its science.

\section{Keynote-Open Geospatial Information: Empowering Decisions and the Economy}

Suzette Kimball, U.S. Geological Survey (USGS)

\section{Linking Science to Decisions}

Suzette opened her presentation by addressing the value of natural resources, spanning from the deep geologic time to recent historic time to the future (fig. 2). It is the responsibility of the USGS to provide scientific understanding associated with those resources. Suzette discussed this role for the USGS as a way to link science to decisions.

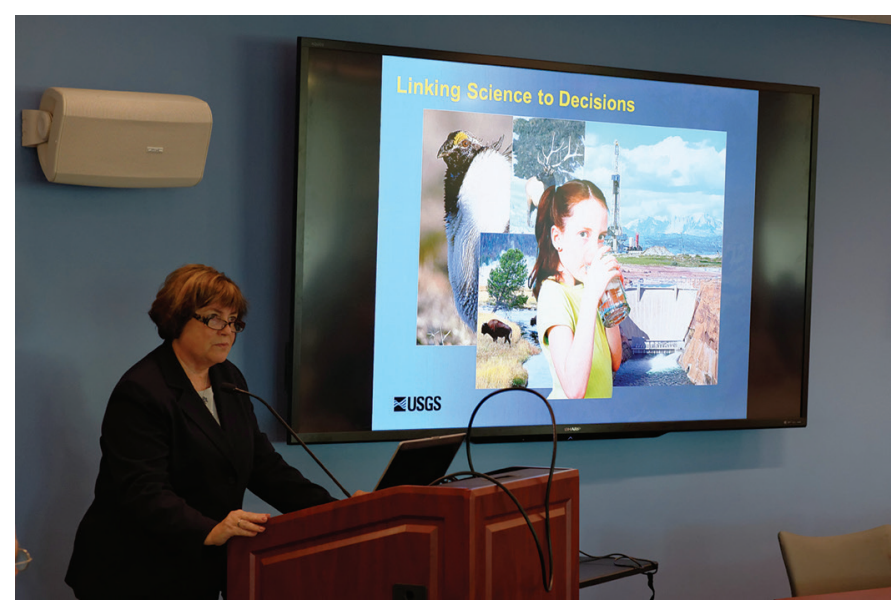

Figure 2. Suzette Kimball, U.S. Geological Survey Acting Director, opens the workshop.

\section{Data Democracy}

Citizens are enhancing scientific efforts. Information from citizens are used to inform a variety of efforts, such as the loss of critical ecosystems, increased need for resources, and other problems, where difficult choices arise. Scientific information needs to be easily accessible and interpreted to inform decisions. This is done hand in hand with a variety of actors, domestically and internationally, broadening communities' ability to understand science. For example, the USGS looked to engage citizens in earthquake monitoring. One in four people in the United States live with the risk of earthquakes. A crowdsourced Web site hosted by the USGS, "Did You Feel It," gathered earthquake information from the public. Impacts from the magnitude 5.8 earthquake that occurred in Washington D.C. a few years ago were shown effectively via rapid and automatic intensity maps based on felt reports submitted online by individuals. With this example and others in mind, Suzette Kimball asked how science agencies could further engage with communities of interest.

\section{Economic and Societal Impacts}

Spatial data are gathered on a variety of scales, and there is a need to understand how socioeconomic benefits of this geospatial data accrue to society. One important focus is to assess the socioeconomic benefit of geospatial information in valuing natural resources. Alternative approaches to achieve this have been discussed in the societal benefits community.

As data become more abundant, "Big Data" can overwhelm users. There is a need to take advantage of such Big Data to make the provided information relevant for decisionmakers and more accessible for communities. An example is the Shuttle Radar Topography Data: local communities can make great use of this information and help economic sustainability in underdeveloped regions.

By making information available without charge or at low cost, benefits can be maximized with an open data policy. Landsat is an example of this. We saw an increase of use of tens of millions of images that are being produced. Once the data have been transformed into usable information, local communities and individuals are able to make better-informed decisions regarding their region. We are coming together globally to embrace open access to data. The general public has a need for this information. Citizen science has been an effective way to expand the number of information users.

\section{Challenges to Consider}

- How can the concept of data democracy be applied to enhance the breadth and depth of users of geospatial and scientific information?

- How can approaches like citizen science and crowdsourcing not only increase the production of geospatial information, but also strengthen the understanding and appreciation of the value of science? 
- How can we evaluate the impacts of geospatial information more routinely and effectively?

- What methodological issues need to be addressed now to better understand the economic and societal impacts of geospatial information?

- What information is most important to assess, analyze, and evaluate the societal impacts of geospatial information and how can it be obtained?

\section{Discussions}

What effect does citizen science have on the USGS budget? Does it cost money or save money?

As citizens become more able to contribute, they become a more effective constituency. For example, if a half million people say that we really need access to, and understanding of, a certain type of information (for example, earthquake early warning), this need provides linkages to the human dimension, not just the geologic dimension. Because politics is primarily local, such large scale requests carry real weight on Capitol Hill. Capital investment upfront is needed, however, to make the systems useful and user friendly. This adds both a human and social dimension to the development and operation of interfaces for citizen-science contributions.

An instructive example of changes in policy and impact on broader access is the availability of imagery data produced by the U.S. Government. The imagery that U.S. agencies once sold is now available for free. What are the effects of providing data without direct compensation? Where would revenue sources come from to replace the lost sales?

Revenue analysis shows there are more than just dollarfor-dollar replacements. Instead of obtaining revenues from the sale of imagery, monetary benefits arise as a general benefit to, and further growth of, the economy at large. For example, by releasing the data at no cost to the user, we obtain information that would not have been available otherwise. In addition to information, new partnerships and interactions occur between the public and private sector, stimulating economic growth.

\section{Keynote-The Emerging Information Environment and Impacts on Decisionmaking}

\section{Nick Sinai, Office of Science and Technology Policy (OSTP)}

Nick Sinai (fig. 3) started his presentation by giving the example of Weatherbill, a company founded by a Google engineer, David Freeburg. Weatherbill was focused on the agricultural sector, producing applications for farmers, helping them to manage yields. Payments were tailored to specific farms. The business would not have existed without open data. The company recently sold for $\$ 1$ billion. Several hundred jobs were created in the U.S. Midwest.

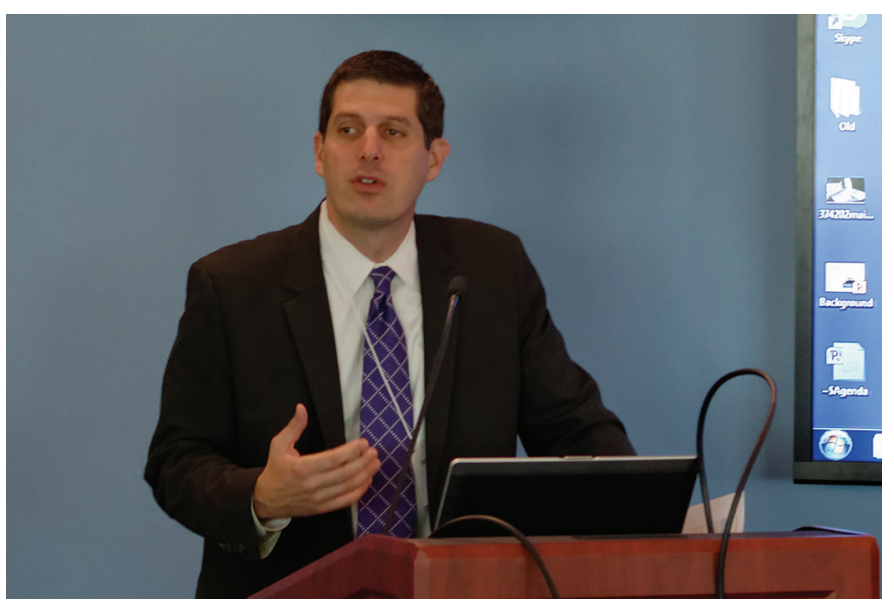

Figure 3. Nick Sinai, U.S. Deputy Chief Technology Officer, Office of Science and Technology Policy (OSTP).

The OSTP signed a memo requiring agencies to inventory data that could be made public. The President supports open data to spur innovation. Data are vast assets in the Federal Government and we are just scratching the surface. The phrase "open and machine-readable" represents the new default (U.S. Department of State, 2012). In the initial directions for new data availability, we should focus on the thematic use (tied to mission), pioneering a few data assets, highlighting those among entrepreneurs and others, to catalyze use. Thinking about it thematically, health, energy, public safety, and so forth, all have open data initiatives. Health care and human services was the first example. The Center for Medical Services (CMS) indicates that open data was key for them to move from "paid by volume" to "paid by value." There is a need for companies to add value.

There are a series of open data initiatives, illustrated by global positioning system (GPS) and weather-data examples. GPS was designed for military and later, opened up, resulting in multiple-fold returns. A traditional application of GPS is in agriculture, and the use of GPS has resulted in significant yield improvements. There are also unanticipated innovations, such as the GPS chip embedded in a dog collar. In a July 2012 report entitled "The social economy: Unlocking value and productivity through social technologies," the McKenzie Global Institute estimated the value of Earth Observation at over a trillion dollars, across several sectors and consumer groups (Chui, 2012).

Nick Sinai suggested the following three points:

Point 1-The administration is focusing rigorously on users of our data (raw data, data products, analytics, and application program interfaces [APIs]) to understand what users need. In the past, information technologists used a waterfall approach - talking to the users and then delivering products up to 8 years later. This created a real problem, resulting in systems failure. Some reports say that over 90 percent of Federal information technology (IT) projects die eventually because of the lack of user focus. We need to understand use cases and consider ourselves users as well. 
Point 2-The public has entrusted us to collect vast sums of data. Although there is a tremendous amount of data dissemination, the majority of data remain within our enterprises. Public-private partnerships are helpful in getting data out to potential users.

Point 3-People are critical as data stewards. They need partners, such as the presidential innovation fellows, who are at the forefront of technology and research and can help the data stewards.

\section{Discussion}

Comparing weather data, which are local and short-term, to climate data, which are long-term, how can we address the long-term needs for open data?

Climate is an important issue for the Administration. It is easy to give a crisp story about weather. For climate, it is more important to make sure that data are available; this leads again to a rigorous focus on the users. Assuming that local planners know what tools they want, the Government acts as a retail provider; this empowers the large companies and startups to develop services. Is there a public interest and what level of retail services should the Federal Government support?

Referencing the data commons model, how can one support the costs of infrastructure?

We are moving to a digital world, requiring peerreviewed science articles, as well as the underlying data, to be publicly available in 12 months. This evolution into the digital world impacts scientists and nonscientists as well, through the research and business information they use, for example, clinical health records and genomic information. Tremendous opportunities in mining the data become available for precision medicine and personalized medicine. Information is categorized into the following groups: nonpublic, restricted public, and public. Mining public data is relatively easy; mining nonpublic and restricted public data is more difficult but with more practical benefits.

We have talked about U.S. open data. What about climate data from other countries India, China, Europe? Is there some sort of reciprocity?

We need to work with other countries. Some have, very small, low-cost satellites, equipped with single sensors, called micro-sats, for example and would like to sell the data collected by the micro-sats. We need to spur innovation in sensor development.

\section{Keynote-Future Evolution of Geospatial Information Sector}

\section{Walter Scott, DigitalGlobe (fig. 4)}

Satellite imagery is not free, but it appears free to most people who view it. The technology is driving demand for "show me where" over "show me what." Big themes include source proliferation, data normalization, and open platforms.

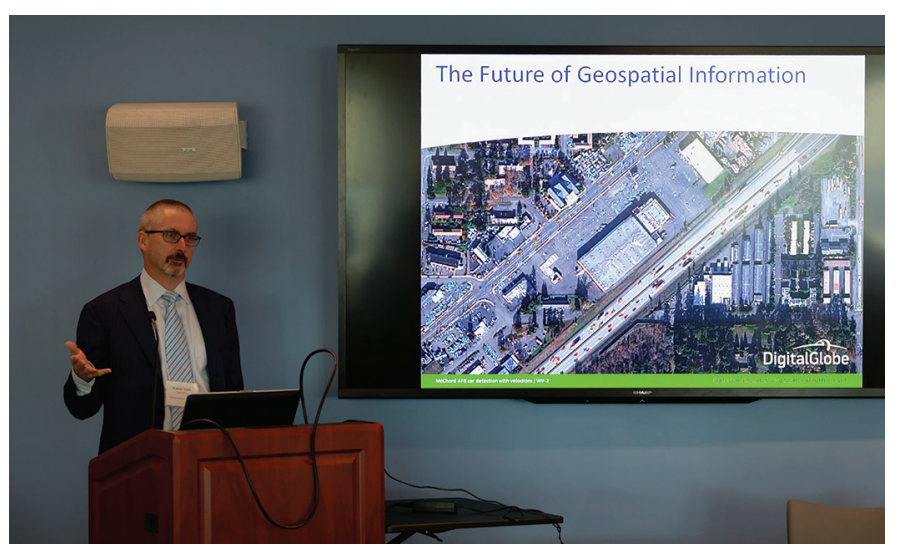

Figure 4. Walter Scott, founder of DigitalGlobe, focuses on the future of geospatial information.

Source proliferation:

- Over 500-percent growth in smart phone usage in 5 years

- OpenStreetMap-crowdsourced maps

- Geo-tagged photos

- Social media—also geo-tagged

- GPS tracks

- Internet of "things"-refrigerators and devices reporting out

- Satellite imagery-Internet of "everything else" (5 billion square kilometers $\left[\mathrm{km}^{2}\right]$ of imagery)

DigitalGlobe has 63 petabytes and is growing. Exponential growth is our friend. Storage makes it possible.

Data normalization:

- Much of the emerging geospatial information is fragmented, inconsistent, and not yet analysis-ready. It may be meaningful to humans but not to machines. Interpretation is a bottleneck to get to machine-ready data.

- Algorithms are enablers; for example, facial recognition requires a large enough training set of data to allow statistical comparison algorithms to work; videotracking.

- Hazy imagery has been unusable and the atmosphere distorts color, based on aerosol and water-vapor distortion. To solve the problem, the atmosphere is measured so that its impact can be determined.

- A number of examples illustrate the leverage obtained from the computers. These include automated image mining of vehicles and their respective speeds - cars are given colors based on speed limit and those traveling in excess of the limit. Another example 
is related to automated building detection, village boundary identification and population estimation.

- Vector data conflation-merge sources.

- DigitalGlobe personnel have leveraged the crowd to quickly analyze an image (hurricane impact) by sending it to a large number of volunteers, CrowdRank sorts between reliable and unreliable sources and then converts the collected information into a damage map, all within in 1 hour.

- DigitalGlobe MH370 statistics.

Open Platforms:

- Geospatial Big Data are too big. The cloud model moves the computation to the data (platform as a service).

Show me Where:

- Geospatial Big Data are a living digital inventory of the surface of the Earth, used for finding, counting, and measuring.

- "Show me where" examples: a picture that wasn't geo-tagged - look at ridgeline, land cover; look at a heat map; risk of where terrorist activities are highest; where farmers are cheating on their subsidies; where copper theft is most likely; where oil theft risk is high; where there are schools near water; where are the people in Kano State (Nigeria)? What kind of neighborhood is this? Is it a favela (slum)?

- Google indexed the Internet. How will we index the planet?

\section{Discussion}

How do you decide the boundary when engaging in a public-private partnership? Where can you make money?

The purpose is to see a better world, go after particular problems to save lives, money, and time. Private companies evaluate many possibilities, addressing problems that are important to customers and aligned with the company strategy.

How about crowdsourcing? How accurate can the first cut be?

A million people are looking at imagery; the crowd acts as a filter; OpenStreetMap, for example, is a wiki and leverages people on the ground (hardcopies of maps are given to local resident to modify). The first cut is not accurate but close enough for the need.

How about the use of time series, for example to analyze pollution trends?

Time series imagery is used frequently to look at landcover specification, and encroachment in areas.

How do you motivate people?

People in the crowd are motivated by a variety of factors, and many just want to help. It is easy to engage a crowd for humanitarian issues (such as search and rescue and public health). The crowd can also be more community-focused. It may be a commercial operation and micro-payments can be used.

\section{Session 1. Impact of Increased Access to Data and New Modes of Consumption}

Chair: Andrew Coote, ConsultingWhere, U.K., introduced the position paper author, and the panel of discussants. Position paper: John Houghton, Centre for Strategic Economics Studies, Victoria University, Melbourne, Australia Panel discussants: Pierre Glynn, USGS; Chris Goranson, White House Innovation Fellow, Department of the Interior (DOI); Sally Wyatt, Royal Netherlands Academy of Arts and Sciences (fig. 5)

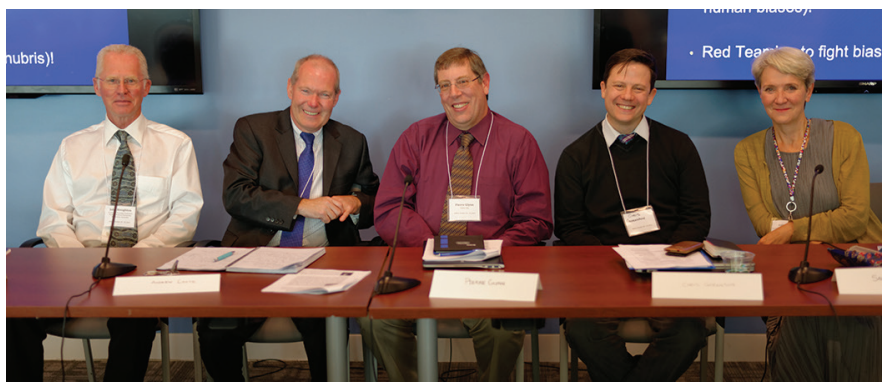

Figure 5. Session 1 panel. Shown from left to right: John Houghton, Andrew Coote, Pierre Glynn, Chris Goranson, and Sally Wyatt.

\section{John Houghton}

John Houghton authored a position paper for the workshop on the impacts of increased access and new modes of consumption (fig. 6). John's research is at the intersection of theory and practical applications. The paper focuses on several aspects of the emerging open-data policy context; John suggested that, while countries confront their own particular issues and difficulties in going from policy to practice and progress is uneven, there is a trend toward more open data (that is, data made available at zero or marginal cost, with unrestrictive licensing, and machine-readable in standardized data formats). There is also a shift toward being more inclusive, especially in the increasing expansion into static content and the galleries, libraries, archives, and museums (GLAM) sector. John noted that there may also be a wide-open data opportunity, based around establishing a regulatory and policy environment conducive to enabling the maximization of opportunities to open private data - both business data and individual data.

In acknowledging these trends, the path forward is not without challenges. Looking at new modes of consumption, John Houghton noted the impacts of online delivery of digital content, the increasing length and complexity of value chains, 


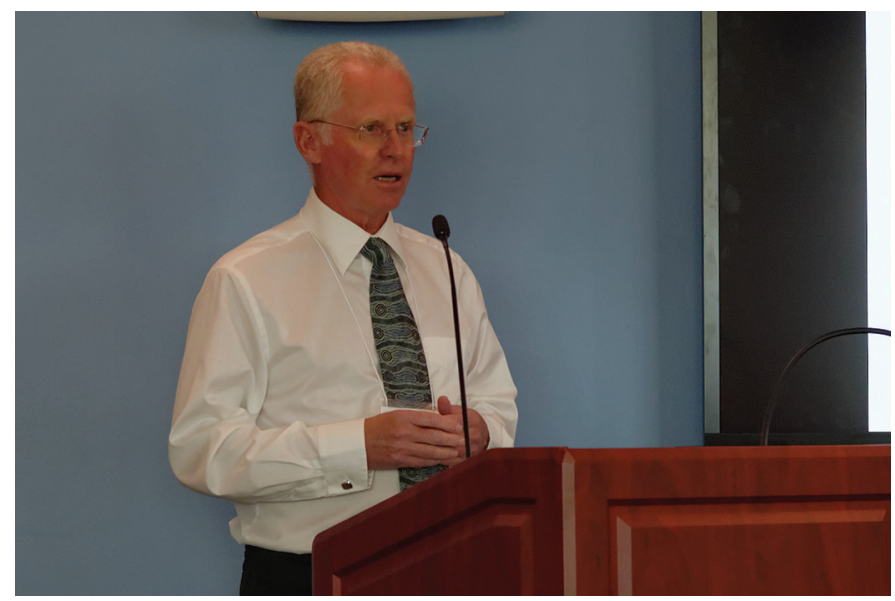

Figure 6. John Houghton presents a paper on the impacts of increased access and new modes of consumption.

and the expanding "shared base." Acknowledging that data are typically an intermediate good, with many and multiple possible uses and combinations of data feeding into many possible production processes, market signals are becoming more varied, fragmented, mediated, and so forth, and much less clear. The paper proposes the theoretical underpinnings of the private versus public tradeoff shifts, with a larger role for Government in the digital economy examined in the context of new data uses.

John's presentation highlighted the key points from his position paper.

\section{Aims and Scope of Open Data Policies}

- Data are often categorized by their sector of production and characteristics. Data can be dynamic (that is, continually generated, such as in business registries), or static (that is, part of an established collection, such as for a library or museum).

- Open data policies seek to foster growth and innovation by making data available at zero or marginal cost, with unrestrictive licensing, and machine-readable in standard data formats.

- There are many open data policy initiatives at the international, national and sector levels, and among national and international agencies.

\section{Open Data Policy Trends}

- Countries confront their own particular issues and difficulties in going from policy to practice, and progress is uneven.
- Nevertheless, there are trends toward

- More open data - at zero or marginal cost, with unrestrictive licensing, and machine-readable in standard data formats.

- Being more inclusive - with an expansion into static content and the GLAM sector.

- There may also be a wider private data opportunity, based around establishing a regulatory and policy environment conducive to enabling open private data (both personal and business data).

- Research focuses on the production of Government data or public sector information (PSI), and the publications and data arising from publicly funded research. Many studies explore evidence of the impacts of open access to Government and research data.

- Methods include the following: ex-ante estimates and prediction (for example, PIRA, 2000), and ex-post evaluations and measurement (for example, Houghton, 2011); top-down approaches (for example, PIRA, 2000), and bottom-up approaches (for example, DotEcon, 2006); qualitative approaches (for example, Beagrie and others, 2008, 2010) quantitative approaches, and mixed approaches (for example, Beagrie and Houghton, 2013a, b, 2014); and, multiple U.K. Research Data Centre studies).

- Methods used by Beagrie and Houghton (2013a, b, 2014) to explore value are summarized in figure 7.

\section{Impacts of Increased Access}

- The evidence from these studies suggests that providing open access to data leads to more use and creates greater value than do priced and (or) restrictive access regimes.

- The main dimensions of impact include the following: transaction cost savings for both data providers and users; efficiency impacts that can be quantified as time-cost savings; increases in the return on investment in data creation from the additional uses that would not otherwise have been possible; potentially significant wider impacts that are more difficult, perhaps impossible, to fully capture; and new applications and combinations of data, with unforeseen value and impacts emerging over time.

\section{New Modes of Consumption}

- Data are typically an intermediate good (that is, a good that is an input to the production of a final 


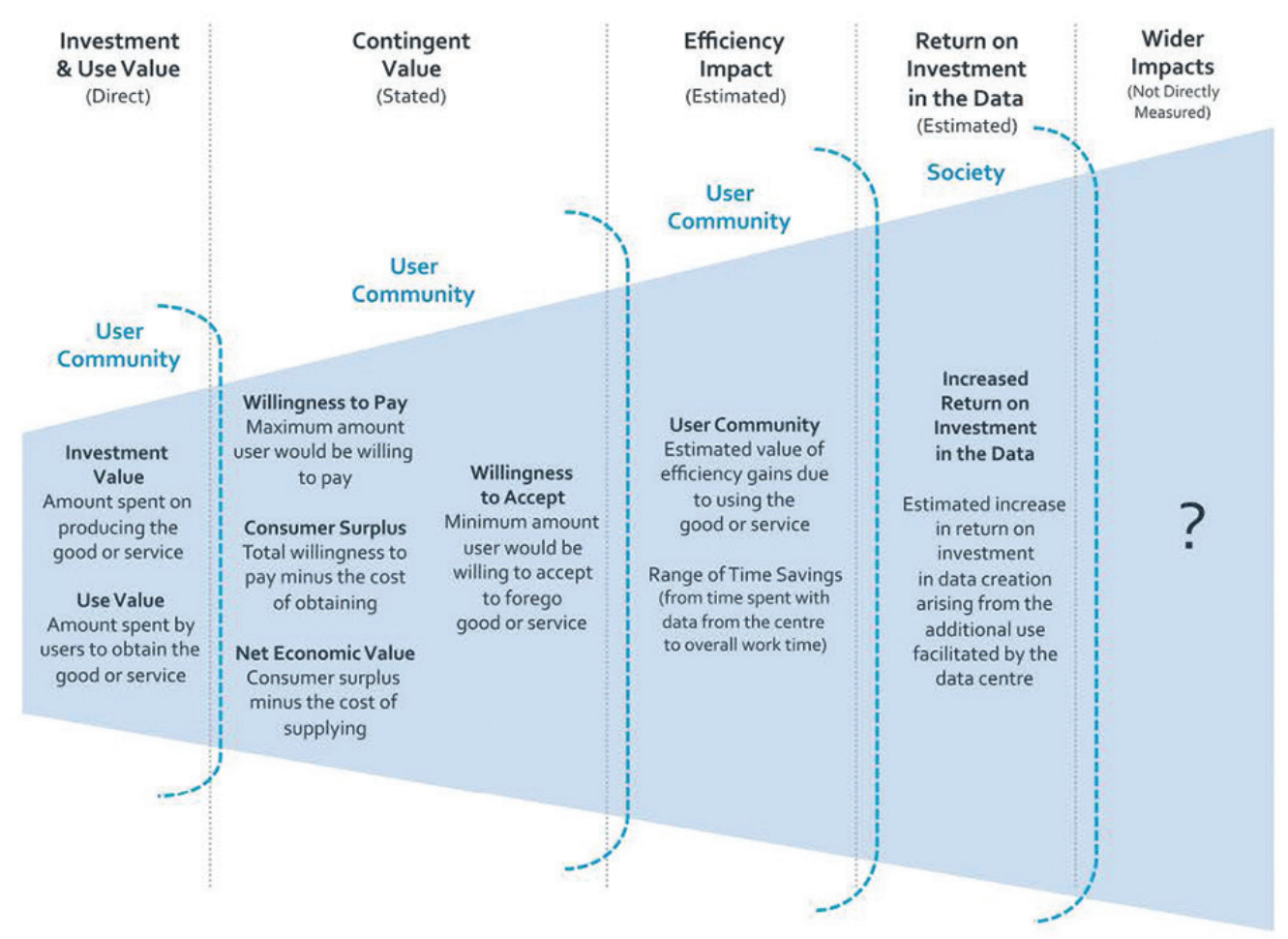

Figure 7. Diagram showing the range of approaches for considering societal benefits. From John Houghton's presentation herein and Beagrie and Houghton (2014). good or finished product), whose consumption takes place in the context of production. There are greater connections in production, with production often involving many inputs and many suppliers and customers, increasing the length and complexity of value chains, and weakening market signals (increasing noise?).

- There is an expanding shared base (that is, an openly available platform providing the basis for production), with open innovation and open access to research, shared IP cores in electronics, open source software, the expansion of fair use-fair dealing and exceptions in copyright, and multiple Internet platforms.

- Digitization and online delivery make content-based goods more like public goods, and the marginal cost of distribution near zero.

- There is an increasing role for Government, as the characteristics of information shift the private versus public tradeoff in a digital economy.

\section{There Is No Such Thing As a Free Lunch}

- Benefits can be reaped from charging for data, in terms of alignment of production with demand, quality, reliability, and so forth.

- Certain uses may be excluded, however, where the capacity to pay is limited or the value of the use is uncertain or unrealizable.
- Nonexcludability creates a free-rider problem, but nonrivalrousness (that is, where a person's consumption of something does not prevent others from consuming it, such as is the case with information) creates a freerider opportunity, which is often much bigger - it is commercially advantageous to give things away.

- Who won't pay for data? Innovative uses for which the outcome is uncertain and there is no established market, or which are themselves public goods, such as research and education.

- A better question might be: How can we find a way to pay that does not raise access barriers and stifle innovation?

\section{Temporal Analysis and Value}

- Changes in value over time-for time-series data, and from new research techniques, new theories and new questions, new commercial uses, and new products.

- Changes in impact over time - counterfactual (for example, World War III), hindsight (for example, thalidomide).

- Rubbish Theory-from transient to durable via rubbish (for example, antique furniture and vintage motor cars, which are purchased and used, depreciate in value, are scrapped, then rediscovered and re-used, and appreciate in value as a result of that re-use). Rubbish Theory (1) suggests point-in-time estimates cannot fully capture value, (2) suggests that value can change 
in unforeseen ways, (3) makes more shapely the distinction between use and re-use, and (4) shows that the potential value of re-use is very difficult to predict. Value can change significantly over time, and the value of re-use is difficult to predict.

- These points, described above, suggest that methods that take account of value perceptions (for example, contingent valuation) might be useful in approaching the value of data.

\section{Skills and Capacity}

- The value and impact of data depend on the skills and capacity of people to analyze and apply it throughout the economy and society.

- Data scientists are often called "unicorns," because the combination of skills required is so rare.

- Universities are moving to modify and create new courses to develop suitable recruits for data scientist jobs, but more could be done on the training side.

- Automation can be an important contributor as a semisubstitute for skilled labor on both the production and use sides (for example, metadata and APIs).

\section{Chris Goranson}

"Data are the grapes, and wine is the information." stated Chris Goranson, who highlighted a number of aspects from John Houghton's position paper. Data "are typically an intermediate good. Rarely, if ever, are data destined for final consumption." Open data are "data made available at zero or marginal cost, with unrestrictive licensing, and machinereadable in standardized data formats." Information can be "a powerful tool in economic growth and competitive advantage." Open access leads to increased use and thus greater value (Houghton and others, 2011). Considering users, with social media as one example, "platforms in which users are not active participants may not be nearly as valuable. Seldom are users active participants in existing Government repositories." If participants can add value, why don't we encourage them to do so? Other models could support the ability of users to define quality and usefulness for new services. They would allow users to create meaningful, derivative, and composite data that can be shared back with Government. There is a variable model in which industry can tell Government what data are most useful and conversely what data are useless. They could provide Government with an information feedback loop. Chris cited Wikipedia and GitHub, where users can copy, share, and improve code, as examples. What if they could do the same for Government data? Chris also showed various visualization implementations that take us from data to information, such as Mode (http://modeanalytics.com), where users can copy, share, visualize, and improve data; and visualizing.org, for which he gave a variety of uses. These included the congressional influences map (BrightPoint Consulting, Inc., 2012) and the open-source GeoGig StoryMap maker software (Geogig.org, n.d.).

Chris concluded by suggesting that how to value information is something that the author should further pursue in a follow-up paper.

\section{Sally Wyatt}

Open access to research data needs to be seen in the larger context of the open access and open science movements, suggested Sally Wyatt. For some years now, people around the world have been arguing for more access to information. Partially inspired by the success of the opensource movement, and with growing calls for accountability from authorities, individuals and groups are looking to make all kinds of data publicly accessible for a wider group of people. This call for more openness includes more access to scientific information, in particular when it is publicly funded. There are global bottom-up initiatives, consisting in particular of activists, technologists, nongovernmental organization (NGO) workers, that collaborate in finding ways of making data available (for example, Open Knowledge Foundation). They believe that open access will be for the benefit of society.

Sally also raised the question of what is meant by open? Open access publications; open research data; open source software; open standards; or open knowledge? Static versus dynamic data is more of a continuum and not as either/or, as expressed in John Houghton's paper. In addition to static versus dynamic, Sally added open versus closed data and gave examples of census and weather data. Only 20 percent of GLAM data may be digitized and the rest is anything but machine-readable. Sally then addressed the economics of the knowledge commons. Rivalry can be low to high; exclusion can be difficult to easy. All of these different possibilities have different consequences in terms of policy. Data are not freefloating items, but rather, are deeply social, always inscribed in the instruments used to create them. Data are interrelated with how they are produced and used. Sally reminded everyone to not forget the work that goes into producing, using, reusing, and curating; noting that considerable labor goes into the upkeep and organization of data. In conclusion, Sally provided the following points for consideration: defining key terms in this debate is not so easy; the practice of open data is even harder; there are distributional implications - between individuals, institutions, disciplines, and countries; learning from philosophy of science, for example, that data do not travel easily; and lastly, there are rational reasons for not making data open. We should look at both successful and less successful instances of making data open and pay attention to technical infrastructure. 


\section{Pierre Glynn}

The position paper is very useful in taking a pulse as to where we are with open data. In summary, the Open Data Barometer ranks key open-access data sites; the paper provides a rationale for data as a public good (nonrival and nonexclusive); and it provides an estimate for the value added by open data. It is suggested in the paper that "As more people, businesses and governments use information to make better decisions, the information becomes more valuable."

Pierre addressed his own views on open data. He thinks quality assurance and quality control (QA/QC) of data is important and should be expanded. More data does not necessarily mean more value, nor better decisions. Taxpayers need to have a return on investment (RoI) and be able to monitor how their dollars are being used. Open data and open access are essential to scientific integrity and progress. They allow checking available data, and potentially, adding new data, or bringing new transformations of the data, or new applications. Taxpayers don't just need access to more data, they also need to be able to explore and use the data smartly, and they need to have confidence in the data made available. Data mining, checking, and analysis tools are essential complements to open data. Pierre stated that his own research is more efficient because of the open access of information through the internet - he uses Web sites, including Wikipedia, to get links to primary source references and then uses Google Scholar and (or) ResearchGate to get access to journal articles and reports. He rarely goes to hardcopy encyclopedias collection for background information, because the information will generally not be up to date.

What about information overload? Information can also be a form of pollution. The Oracle of Delphi shows that people often attach more value to things they need to pay for; and they may get better answers when they are engaged to think. The Oracle of Delphi institution lasted at least 12 centuries on sparse cryptic answers and restrictive access. Today's science requires greater transparency, more approachability, and diversity of perspectives, but some of the Oracle's lessons remain.

Open data increasingly defines our new world, with 7 billion hyper-connected people. The way science happens today is different than in the past traditional model. Pierre showed the Funtowicz and Ravetz (1993) diagram (fig. 8) in which the vertical axis illustrates decision stakes and the horizontal axis represents the level of uncertainty - circular "waves" (shown as quadrants in fig. 8) extend outward from normal science to expert-professional judgment to post-normal science with uncertain facts, disputed values, high stakes, and urgent decisions. The diagram shows the role of different types of science in the continuum from data to information to knowledge to decisions and to action. For managing the commons, a top-down approach does not suffice. We need more bottom-up approaches. Good implementations of "open data" and "open access" require addressing their human dimensions much more fully. Such dimensions control the true

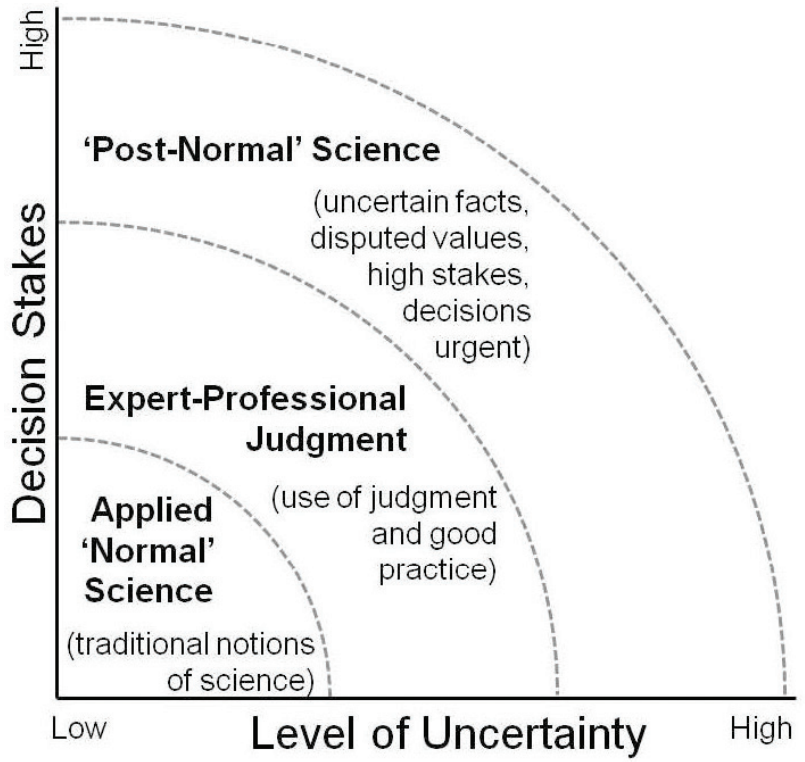

Figure 8. Graph showing movement from traditional notions of science to science with uncertain facts, disputed values, high stakes, and urgent decisions. From Pierre Glynn's presentation, herein, and modified from Funtowicz and Ravetz (1993).

accessibility of information, and even more importantly, its meaningful and smart use for decisionmaking.

\section{Discussion}

How could we measure the value in data?

Robert Solow's economic growth model was referenced. Static versus dynamic data is a continuum. Typically, we start with the dynamic part; it is captured in a digital form so we can do something with it. Measuring what you can value as in a cost-benefit framework is better than not doing it at all.

Measuring the value of data depends on skills and capacity of people to analyze the data. Can we have too much data and how do we deal with that? What is the cost of too much data?

How do we address these questions? Better education; more joint posting and uses involving both experts and members of general public; structured, transparent, traceable, coordinated processes that strive for honesty, including cognizance of human biases and red lining to fight biases.

What about the role of open source-like wiki's without Government control? Can industry tell the Government what to do and show a better way to do it? The private sector does the implementation, whereas the Government has a unique role in providing a balance. It is a lot of work to make data open; is it always worth it?

In astrophysics, there is a national virtual observatory; a context was created that encompasses it - a 3D spatial visualization; they made a virtual camera that can fly into the data, enabling the world-wide telescope to be accessible (http://www.worldwidetelescope.org/Eyewire/). One of our 
participants thought that we would be talking about different business models for different users. What type of business model should we be offering? That is an important and difficult question. It is difficult to come up with good business models. Open data and access is the default, with marginal cost for the worst case. How do we prioritize what we create, that we feel is valuable enough to curate? Should we give away information and sell data?

\section{Concluding Remarks}

- The position paper includes a lot of material for discussion.

- Can we rebalance public-private partnerships around open data?

\section{Session 2. Increased Supply of Geospatial Information and Expanded Participatory Processes in the Production of Data (Such as Crowdsourcing)}

\section{Chair: Carl Shapiro, U.S. Geological Survey}

Position paper: Lea Shanley, Presidential Innovation Fellow at National Aeronautics and Space Administration (NASA), and University of Wisconsin-Madison; Max Craglia, European Commission-Joint Research Centre (EC-JRC)

Panel discussants: Mikel Maron, Presidential Innovation Fellow with the State Department and OpenStreetMap team; Robin McLaren, Know Edge Ltd., U.K. (fig. 9)

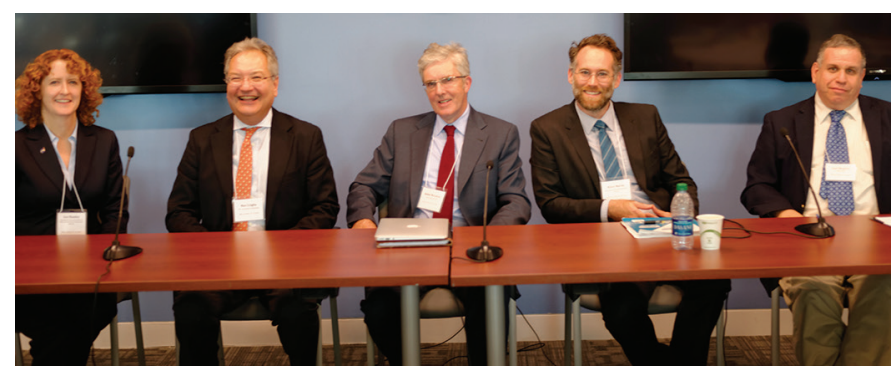

Figure 9. Session 2 panel. Shown from left to right: Lea Shanley, Max Craglia, Robin McLaren, Mikel Maron, and Carl Shapiro.

\section{Carl Shapiro}

Although satellites and sensors have exponentially increased the quantity of geospatial information available, public participation is transformative because it can enhance the use and value of the information decisionmaking. Public participation can increase understanding and application of the information and at the same time it can add critical information through techniques like crowdsourcing. It also can expand and broaden the range of beneficiaries from the information as wider groups of individuals become knowledgeable about its existence and utility. The paper explores these opportunities as well as many issues that arise in using data generated by the public: Can the "wisdom of the crowd" improve the quantity and quality of data available? Can it be relied upon? What are the risks? What are the benefits? Is it sustainable? What are the quality aspects to consider?

\section{Max Craglia}

Max Craglia gave the position paper presentation titled, "Data democracy-Increased supply of geospatial information and expanded participatory processes in the production of data" (fig. 10). He started with a short introduction on the European Union.

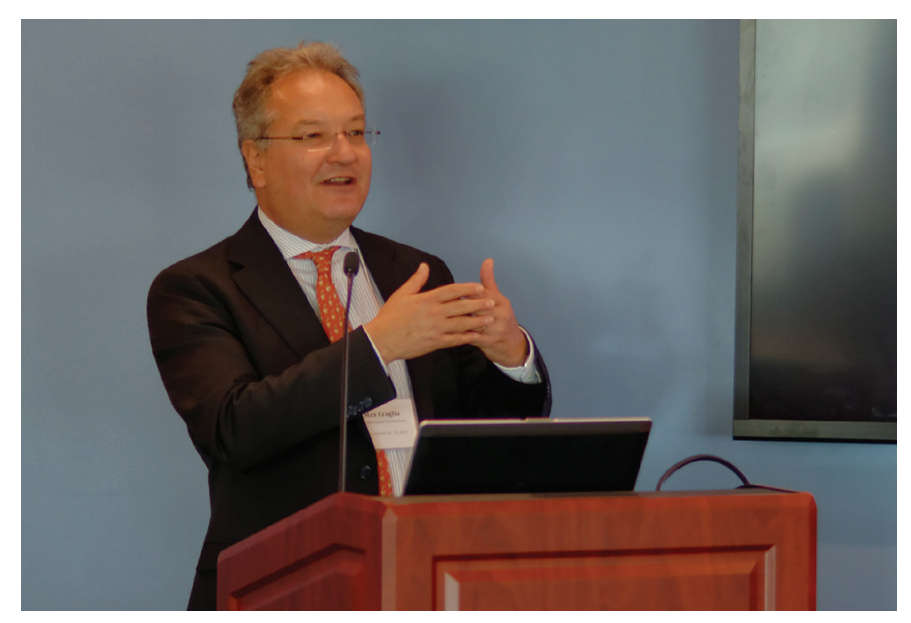

Figure 10. Max Craglia presents a paper he developed in collaboration with Lea Shanley.

Citizen science is part of the changing data landscape. There are many new sources of data, in the public and private sector. There has been a huge increase in the volume of data, including data from new satellites and sensor networks. In addition, the "Internet of things" will further contribute to this. According to SINTEF (SINTEF, n.d.), 90 percent of all data in the world were collected in the last 2 years. Crowdsourcing and citizen science are not just about more data, but are about new and collaborative modes of production and consumption. People are both users and producers of information; the Internet has allowed their contributions to increase.

In Europe, people talk about citizen science as a single concept; however, there are different views of citizen engagement. The purpose may be more focused on raising awareness and (or) education; community-led projects, cooperating with universities; and crowdsourcing in which citizens are involved in data production. Data mining in social media is arguably not citizen science.

The extent to which communities participate is an important marker. Four levels have been identified: crowdsourcing, distributed intelligence, participatory, and "extreme." In the latter, the citizens contribute in the definition of the problem. 
The discussion on genetically modified organisms (GMOs) in Europe was given as an example. Most people are not concerned about the safety of GMOs, but they are interested in who is benefitting and controlling them and what the long-term issues are. For this issue, is quality a problem? Not necessarily. Is the methodology good or bad? Quality has to be assessed in relation to the objectives.

\section{Open Issue}

Reproducibility can be difficult; sustainability of engagement for a volunteer operation must also be considered.

\section{Points for Discussion}

How do we empower communities to collect, analyze, and understand data to improve lives? How do we involve people in the framing of the questions as well as collecting data? What kind of infrastructure is appropriate for sharing data, and methods? How do we foster multi-disciplinary thinking? Do we need educational programs in school on citizen science and data management? Are the existing regulatory frameworks adequate? How can we design an international research program on the value of citizengenerated content for policy, science and society?

Finally, we are living in a society that is increasingly polarized, with lack of trust between society, science, and policymaking. There are many "wicked problems" in which facet, interests, and values are inextricably meshed. Citizen science could be a way to build bridges between communities. Are we as a society truly prepared for the challenge?

\section{Mikel Maron}

Mikel is looking through the lenses of OpenStreetMap, which is essentially the Wikipedia of maps. From a crowdsourcing standpoint, it is an "extreme" project. OpenStreetMap was started 10 years ago by a college dropout using a GPS and walking the streets. The goal was to map the entire world using a community of walkers, hikers, canal boat operators, humanitarians, and so forth. The focus was on physical infrastructure and land use (what you can see with your own eyes or from the sky). OpenStreetMap treats data as a conversation by using a flexible system of tags. Nobody is in control of the schema. The representation is enclosed in the tools.

Mikel Maron argues that issue of data quality raised by some is a red herring. The expert is the person who participates and lives in a certain place. Acknowledging the voice and needs of the community helps them advance their agenda. Without applications such as OpenStreetMap, the wealthier, safer areas are mapped while the poorer, more dangerous areas are not.

Open Cities Project in Sri Lanka and Nepal uses the approach of engaging with Government, schools, and communities to collect map data and prepare for inevitable disasters. Participants have taken on the responsibility of engaging with these communities.
There are questions of sustainability. What is the value of the mapping products created by crowdsourcing? (How much would it cost if the product was produced commercially?)

\section{Robin McLaren}

Robin McLaren noted that the session 2 position papers had several gaps - especially in the crowdsourced open data domain where considerable value can be added through networks based on trust, protocols, and rules. Crowdsourcing is morphing into ecosystems that add even more value. The discussion is given through the lens of democratization of real property rights. Seventy-five percent of the world's population does not have access to secure land rights. MapMyRights is a foundation project Robin is working on and his current activities consist of the U.S. Agency for International Development (USAID) Mobile Project, three pilot projects in Tanzania, Cloudburst, and more. Socioeconomic benefits associated with documentation of property rights include the following: increased security of tenure for citizens and communities leads to social stability; reduction of poverty; better land governance; reduced risk of land "grabbing"; and lastly, the ability of children to devote time to school rather than guarding property. Trust-based systems are replacing legal-based systems to fill this current tenure-based security vacuum. The earlier initiatives avoided open crowdsourcing at the outset by asking land professionals and (or) NGOs to train trusted intermediaries in communities and self-organize into collaborating networks. Robin showed a continuum between informal and formal land rights. Crowdsourcing is a launching pad on this continuum that can support a person moving toward formal land rights. Crowdsourced data support a Fit-For-Purpose approach (participatory, upgradeable, and affordable). There are unintended consequences, howeverpeople may misrepresent ownership by recording claims for land that is not theirs and some slum dwellers want to hide. These issues will have to be managed effectively to build trust in this open approach.

In conclusion, it is possible for trust-based systems to serve as entry points for legally based systems and incrementally build value.

Passive data can be mined and used in many different ways. Their value was estimated to be worth $\$ 156$ billion in 2012 ( $\$ 500$ billion in 10 years) and represents $\$ 60$ for each of the world's 2.5 billion Internet users. If we estimate that 25 percent of this revenue is directly related to location information, then passive location information is worth $\$ 40$ billion/year. Citizens should be compensated for use of their passive location information.

\section{Discussion}

Lea Shanley is very aware of unintended consequences; there is an intellectual property issue, as well as a political issue. She gave the example of unmanned aerial vehicle (UAV) monitoring of private properties. 
Max Craglia indicated that there are transferrable skills coming from these citizen science and (or) crowdsourcing activities, which are increasingly needed for tomorrow. An area of concern is the shift to an economy built on personal data collected and used by the private sector, in which we as citizens are the commodities and no longer the subjects.

One discussion focused on the role of governance in data and in creating opportunities for social and economic impacts. This is, in part, balancing the roles of the public and private sectors. A possible foundation is for the Government to provide a geographic framework. Other factors for broad uptake are to adjust the tools to make maintenance fun; create partnerships to address imbalances in participation and resources; and work with after-school programs - education is key. There are incentives at the local level regarding, for example, roads being paved or trash being picked up. An important role of the Government is to fund the data collection, including collection of baseline data, as well infrastructure and archives; just setting the standards will not be sufficient. There are other models, such as the Dutch Key Register that is definitive, authoritative, and free to use. In this case, Government is the custodian for this information and the framework to tie it together. In the United Kingdom, data collection is outsourced. For data collection from nonstandard sources, citizens involved in scientific projects have been generating the testable hypotheses, as well as providing citizen sensor data and other information. Are there activities that are best suited for different types of participatory processes? Citizens may be best at identifying societal impacts. Is there use in assessing value? It is often hard to tease information from data. In addition, there can be unintended circumstances that impact the collected data and resulting information. (For example, squatters in underdeveloped countries do not necessarily want to divulge where they live.) Lastly, volunteer citizen scientists may require expert coordination.

\section{Perspectives-A Dialogue Between Panelists}

\section{Chair: Jay Pearlman}

Panelists: Molly Macauley, Resources for the Future and Jim Geringer, Esri (fig. 11)

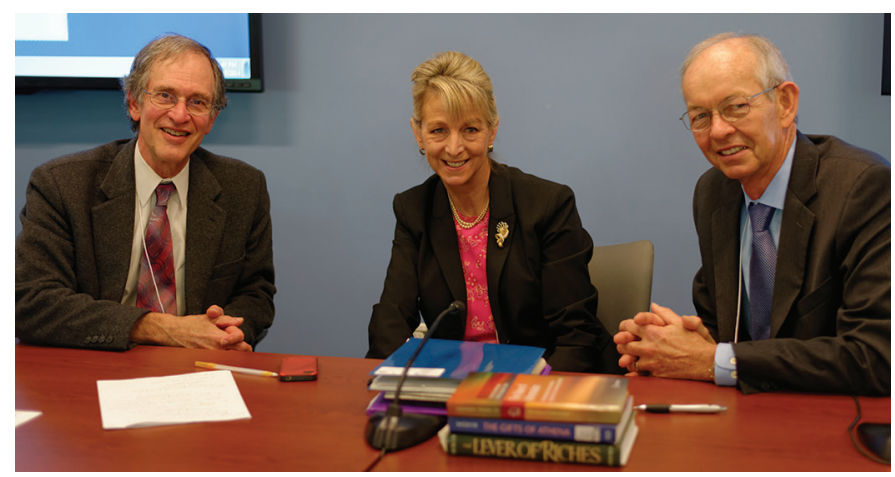

Figure 11. Perspectives for the workshop panelists. Shown from left to right: Jay Pearlman, Molly Macauley, and Jim Geringer.

\section{Jim Geringer}

How do we assure the data being gathered is worth something? Do we know its worth? It is important to personalize the context so one recognizes the purpose of the data collection exercise. "Information within context is the most powerful visualization of all."

The gap in understanding of "what is crowdsourcing" is narrowing considerably. How do you answer the question "What is the value of GPS?" Valuing these services is very important.

\section{Molly Macauley}

The pace of technological advances is ahead of policy advances. The capacity to handle data was not expected, and this leaves us behind. It reminds us, as we look ahead, to anticipate technological advances. We are led to a profound policy question: Where do our decisionmakers invest in the next generation infrastructure? At the margin, what will we do? When will the private sector and nonprofit sector be more broadly engaged?

Today's discussion was focused on technological advance with respect to spatial detail. Temporal and spectral data characteristics are important considerations as well. These are the "wave of the future." Now we can describe the data in more detail, rather than focusing on the averages. When we augment Earth-observing systems, where do decisionmakers invest in the next generation of infrastructure? Should there be a bureau of environmental statistics? Creating one may help avoid duplication of effort.

There is value in having data collected over time. Respective responsibilities to collect and archive the information must be adjudicated between the public and private sectors.

\section{Discussion}

How can Federal agencies communicate the value of their distributed data to decisionmakers on Capitol Hill?

The recommendation is to illustrate the value of data with a story which decisionmakers can relate to. For example, what is the value to somebody back home? For decisionmakers, value is subjective in many ways. The difference between value and perceived value is very important. The key is to give options so users can select according to their perceived values. It could be said that value is created when an agency offers data and users want more.

As an agency example of value creation and flow, there are instances where the Federal Emergency Management Agency (FEMA) is using data to draw flood maps. FEMA uses geospatial information for first responders; thus, the ultimate value assessment is at the local level. Part of the issue is how and when to address risk management for applications. Integrated risk management means you integrate it in context.

Packaging the message, tools, and data, there is consideration of value versus ease of use and (or) access. Agencies do not do that; it is the duty of scientists to share 
information derived from data with the public. In turn, this information can help the public inform science.

Some key points of the discussions related to the way the information is used - should there be stricter regulation to protect personal data? The problem is primarily enforceability.

In summary, value is subjective; data should be given as options for decisions.

Engage the social, economic, and political sciences as well as natural sciences; consider public-private sector partnerships.

\section{End of Day 1}

\section{Day 2-October 29, 2014}

\section{Welcome to Day 2}

\section{Tim Stryker}

Tim Stryker gave a short introduction to the U.S. Group on Earth Observations. He mentioned the Federal initiative on climate, and talked about discoverability of datasets that agencies are holding. The Global Change Information System supports the outcome of the climate assessment.

Regarding socioeconomic benefits, Tim appreciates the work the team is doing to define the value of information. We cannot assume the value of Earth observation and geospatial data; the value needs to be adequately quantified. What do we value as social goods and how do we explain their value to policy makers?

Tim Stryker then addressed OSTP's work on civil earth observation policy and planning. The NASA Authorization Act of 2010 updated the strategic plan for Earth Observation (EO). The OSTP was asked to evaluate civil observations for the Nation, which was a beneficial catalyst. The 2013 Earth Observation Strategy followed (Executive Office of the President National Science and Technology Council, 2013), providing a societal benefits framework and guidance for data management (use of machine-readable formats; increased inoperability). Publicly funded data are open.

The National EO task force is providing Federal-wide assessment for nine societal benefit areas (Federal and nonFederal) looking at impacts from streamgages to satellites. The national plan for EO was released in July 2014 (National Science and Technology Council Executive Office of the President, 2014). To help accelerate implementation, a Big Data Initiative was started (fiscal years 2014/2015). Making data freely available is not free by itself; there is a need for standard curation practices across agencies.

\section{Discussion}

The data working group is taking a comprehensive look at data discoverability and usability. The Climate Data Initiative focuses attention on particular aspects of this. There is a plan to provide Federal Government-wide metrics on usability over the next 18 months.

\section{Day 1 Summary}

\section{Lawrence Friedl}

Lawrence added his perspective to the comments given by Molly Macauley and Jim Geringer on the first day (fig. 12). The entire workshop is addressing the linking of information to decisions and actions. This includes both the value of that linkage and the valuation of the resulting actions, such as the ability to value natural resources and natural-resource assessments (Suzette Kimball's points). From Molly's opening, we heard about the increasing supply of data and, hopefully, information. In many ways, Day 1 focused on the supply side, increasing supply through open data and the engagement and participation of the "crowd." Today, by comparison, will focus on demand side.

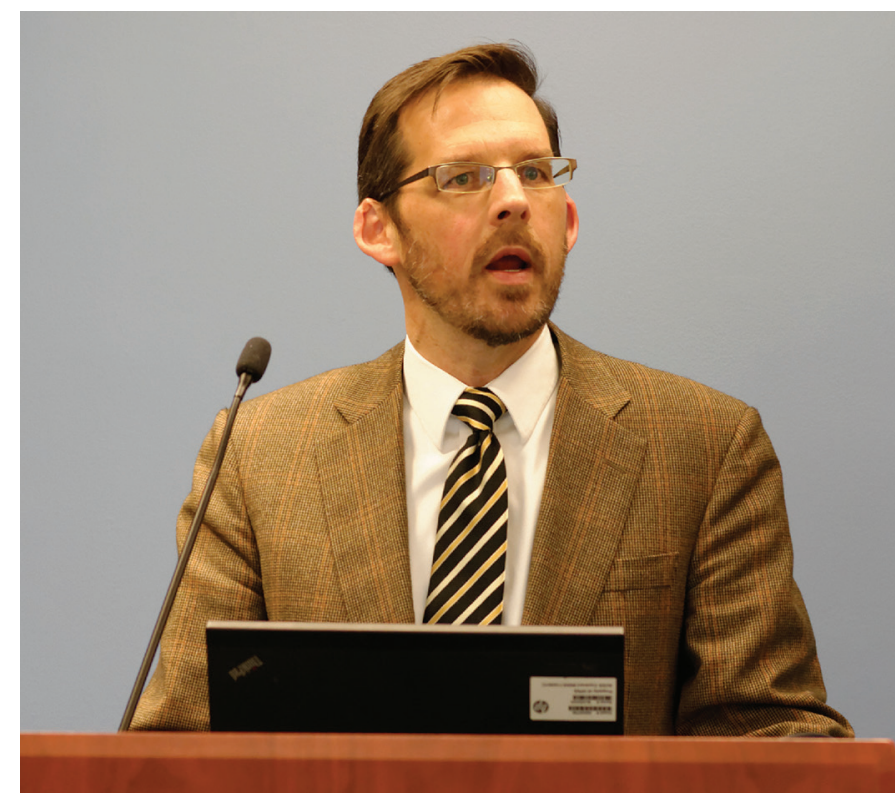

Figure 12. Lawrence Friedl gives his perspectives on the first day of the workshop.

We recognize that, for the Earth science community in the United States, open data-from Government and publicly funded research or observations - has been part of the culture since the early 1990s, and that the Internet accelerated the process. As John Houghton suggested, there is a tacit assumption that open data supports greater use, and that greater use spurs greater innovation. In Nick Sinai's talk, as well as in one of the Birds of a Feather lunch session discussions, we did get reminded that not all publicly collected information can be shared - that there is public, restricted public, and nonpublic data. Thus, although there is an inherent attraction of openness, there are limits to it.

So, do we need to value open data? Certainly, as we encourage other countries to share their data and adopt our approach, both for their gain and ours. In addition, with recent economic and budget crises, there were again calls in Congress for Government to charge for certain data. Thus, 
although the policy debate is for open data for now, the valuation analyses need to be ready if proponents of that policy want it to continue.

In Day 1, overall, some points serve as good reminders to us. Walter Scott noted that, such as in the case with satellite images on Google Maps, "Open data is not always free data." In addition, Jim Geringer and others noted, there is the real, financial impact in the loss of a revenue stream for that organization providing the data, even if the benefits to society, innovation, and the economy dominate.

In the first panel discussion, John Houghton showed that many studies explore evidence of the impacts of open access. After talking about the main dimensions of impacts, John reminded us that, with data, the consumption rarely takes place in the context of production and that data are typically an intermediate good. Following that thought, Sally Wyatt reminded us of the critical importance of the data systems manager. The work of producing and caring for data are undervalued. This situation has been identified by the Earth Sciences Information Partnership (ESIP) Federation in the United States as needing attention.

Panel 2 gave us an excellent overview of the citizen science movement. Max Craglia and Lea Shanley provided a useful typology of citizen-generated content projects as well as the dimensions of engagement. Everyone on the panel and a few members of the audience referred to the work by Muki Haklay at University College London. Among the important points that Max left us with was that citizen involvement is, in part, about helping to clarify the questions to address. Members of the panel and some workshop participants noted that there are specific places where citizen science is appropriate and others where it is not. Participants also recognized the involvement of citizens as a key marketing tool to better connect the public to the scientists' work. Mikel Maron showed the efficiencies and positive contributions that crowdsourcing provided in the case of open street maps, and Robin McLaren discussed trends in the socioeconomic valuation of crowdsourced data. Robin noted that the crowd is morphing into ecosystems.

Some key themes that recurred through the presentations and panels include the following:

- Participation and participatory approaches

- Public-private partnerships

- Capacity

- Role of Government: when to be the provider or collector; when to be the custodian and quality assurer.

- Serendipity of innovation from open data, civilian science, and crowdsourcing. Although, as a science policy or technology policy, serendipity of innovation doesn't help you identify which measurements to collect.
Right before the end of the day, Jim Geringer raised an important point - that there is a difference between value and values. Science and technology can present options to a decisionmaker and politician, although the decision itself is based on the policy-maker's values - what is his or her calculus of all the economic, social, scientific, and political factors. Although science and data and analysis can inform that, they cannot trump the value basis the public official has.

As we circle back to Suzette Kimball and Nick Sinai's remarks, we return to a focus on users. While talking about the supply chain, Suzette talked about the challenge to enhance the breadth and depth of users of geospatial and scientific information:

- How do we know when we are being effective?

- How do we know which information is valuable?

- How do we distinguish what is important from what is not relevant for the issue at hand?

These are the points that lead us into the Day 2 discussions.

\section{Discussion}

We mentioned marketing. What does marketing mean in this context?

It is a better understanding of users, or consumers. When we do market studies, we are looking at values and perceptions. Based on a range of decisions, what are the different methods, such as building case studies in geospatial/ science communities? To achieve a better collaboration between social and EO science communities, what are the appropriate tools to make one's case? What can help prioritize measurements we need that can be advocated on Capitol Hill? We should lead with the analysis and close with a face on it.

Jay Pearlman, session chair, introduced the keynote speaker.

\section{Keynote-Social Impact of Information Abundance}

\section{Myron Gutmann, University of Colorado, Boulder}

People keep talking about increasing volumes of data, as said by Myron in his introduction (fig. 13). How do we move beyond the abundance of EO data to an integrated approach? Valuable findings can be obtained by combining societal information with environmental data. Myron identified four significant impacts of information abundance regarding innovation and economic growth, data-driven public knowledge, data-driven policy making, and data-relevant learning.

Big Data examples include the data produced by the Large Synoptic Survey Telescope (LSST) in Chile; the 1.23 billion monthly Facebook users; the billion plus people IPUMS (https://www.ipums.org) has data on; the building shape data from OpenStreetMap; and the data from Google. 


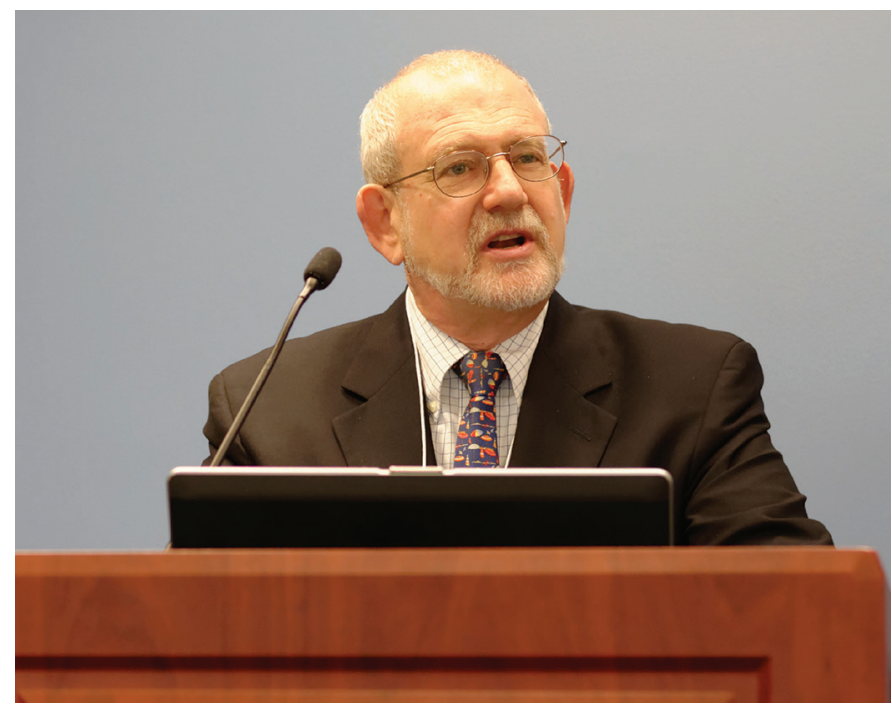

Figure 13. Myron Gutmann gives a keynote address on the impact of information abundance.

Steve Koonin, at the Center for Urban Science and Progress at New York University (NYU), identifies data integration as the key to future science, policy, and civic engagement. Broad sets of sensor data are output from our instrumented cities (many different kinds of sensors), and integrated with other sources (transportation, traffic) for visualization.

A National Science Foundation (NSF) project (Terra Populus) links population census micro data and environmental data (land cover, land use, climate data, and so forth). A lot still needs to be done, such as understanding the social environment. To understand the complex policy setting is important. How do you protect confidentiality and also acquire data?

There is a lot of information, but it is not consistent in terms of what you can predict from it. Myron gave the example of flu trend predictions from Google (Google, Inc., n.d.) and several others. The public is increasingly engaged by data because of its abundance and their ability to analyze it.

Myron focused on the four significant societal impacts of information abundance, giving several examples: more economic and technological innovation and growth (not much more at this point); more data-driven public knowledge; and more data-driven policy-making. In addition, the demand for data-relevant learning has increased in schools. For example, the University of Colorado College of Media, Communication and Information has created a new major in this area in Arts $\&$ Sciences alongside the one in Computer Science, and 400 students signed up for it.

In conclusion, what do we need to do to lock in these societal impacts? Continue information abundance, adding more details and enhancing data integration. Continue to add human capacity for data analysis and public engagement. Be mindful to protect confidentiality and privacy, and be sensitive to cultural context.

\section{An Interactive Discussion on Data Impacts on Decisionmaking}

The discussion included Camille Touton of the Department of the Interior; Bob O'Connor of the National Science Foundation; and Al McGartland of the U.S. Environmental Protection Agency. The discussion was facilitated by Claire Jolly of the Organisation for Economic Co-operation and Development.

Camille Touton, Counselor to the Assistant Secretary for Water and Science at DOI, talked about how to discuss scientific results with elected officials. Translating budget line items into actual values, in economic and societal impact, are hard to do. Access to data and interpretation of data are important to Congress. Camille mentioned the example of the Open Water Data Initiative, which is part of the President's Climate Action Plan. There is an attempt to make datasets more uniform. There is a difficult balance between advocating for science and the integrity of the science. Scientific integrity cannot be compromised, so advocacy must come from outside the system.

Al McGartland, chief economist at the U.S.

Environmental Protection Agency (EPA) regards the EPA as a customer for data as well as a regulator. The EPA does research using tools, such as cost-benefit analysis, to evaluate the efficiency of environmental regulations. For example, they are monitoring refineries' real-time impacts on local populations (birth weight is impacted by exposure to toxins). $\mathrm{Al}$ notes the difference between observational data and model data. Valuing environmental ecosystem services is important.

Bob O'Connor indicated that although there are benefits to geospatial data, it is not certain that more geospatial data always lead to better decisions. He raised a number of illustrative questions. Has it led to better decisions for zoning, health, or EPA regulations? Further, the data may be accessible but not usable. There may be too much data. Open geospatial information may benefit terrorists. Has the technology increased or decreased inequality?

\section{Discussion}

Public trust is down everywhere. It is more difficult for scientists to say, "Here are the data and here are the uncertainties" and be listened to. There is an old adage about "trust but verify." It is important to link the data value chains to the decisions.

\section{Session 3. Emerging Approaches for Economic Impact Assessments}

Chair: Claire Jolly, Organisation for Economic Cooperation and Development (OECD)

Position paper: Richard Bernknopf, University of New Mexico; Carl Shapiro, USGS 
Panel discussants: David Arthurs, Hickling Arthurs Low, Canada; Benjamin Simon, DOI; Larry Sugarbaker, USGS (fig. 14)

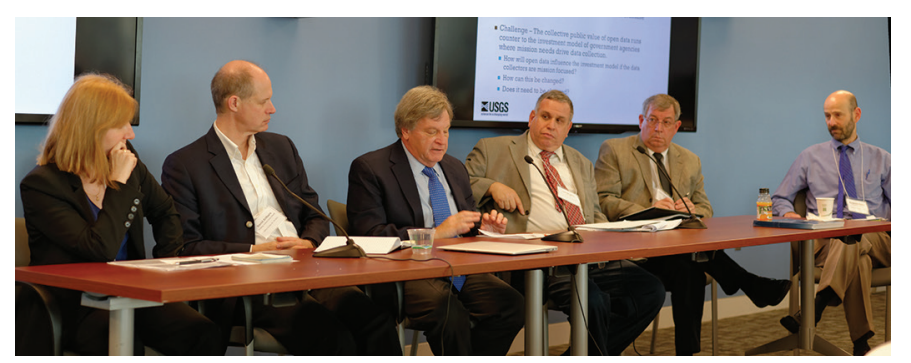

Figure 14. Session 3 panel. Shown from left to right: Claire Jolly, David Arthurs, Richard Bernknopf, Carl Shapiro, Larry Sugarbaker, and Benjamin Simon.

\section{Richard Bernknopf}

Decisionmakers can be better informed with geospatial data. The position paper describes an economic model that involves application of spatial and temporal scientific, technical, and economic data to better inform decisionmakers (fig. 15). The value of information (VOI) is determined as the difference between the benefits of a decision with and without the data. An economic model that describes the value added of geospatial data in decisionmaking is applied in three examples: (1) a retrospective model about environmental regulation of agrochemicals, (2) a prospective model about the impact and mitigation of earthquakes in urban areas, and (3) a prospective model about developing privatepublic geospatial information for an ecosystem services market. Each of these examples demonstrates the value in use of geospatial information within a decision framework. Economic values are established in specific applications in an empirical economics approach as the basis for the value in use of the information. The method has two stages; the first

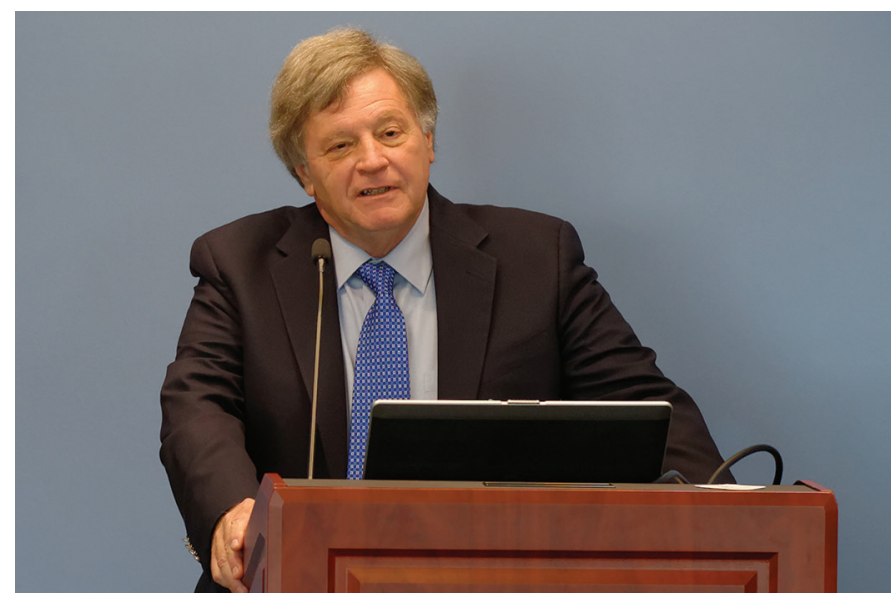

Figure 15. Richard Bernknopf presents the position paper on emerging approaches to economic assessment developed in collaboration with Carl Shapiro. is the development of an interdisciplinary model of economic behavior in which the application of the geospatial information is demonstrated as a consequence of spatiotemporal observations. The second stage is to estimate the net benefits with and without the geospatial information or VOI. The VOI of geospatial data in use for decisions is the focus of this paper.

Geospatial information is an intermediate good that has public and private good attributes. General geospatial information is a public good; however, specific geospatial information can be a private good. The value of geospatial information is determined as the impact on final (consumption) goods. The economic value of geospatial digital data is a technological innovation that contributes to an increase in the efficiency of the production of a final good. Determining the economic value of the information requires an understanding of its use in producing the final good. Empirical applications for specific decisions are needed.

Rich Bernknopf gave three case study examples:

1. An inductive retrospective model-Environmental regulation of agrochemicals: Geospatial data provide information for regional environmental and health policy decisions.

2. An inductive prospective model-An application to earthquake hazards mitigation and income distribution: Geospatial information provides input for earthquake housing risk concentration in a hazard scenario.

3. An integrated market model for ecosystem services markets-An application of geospatial information can provide an objective, replicable accounting framework to reduce transaction costs in environmental market(s) activities.

\section{Case Study 1}

- In the first example, the issue is whether moderate resolution land imagery can provide economic benefits to society. The case study focuses on maximizing agricultural production (corn and soybeans) in Iowa, while sustaining potable groundwater according to EPA standards:

- Application of nitrogen to crops, when leached, transforms into nitrate, which reacts with other chemicals to create carcinogenic compounds.

- EPA health standard: Nitrate concentration in drinking water cannot exceed 10 milligrams per liter $(\mathrm{mg} / \mathrm{L})$.

- Moderate resolution land imagery (MRLI) - Spatial data having a pixel resolution of 30 to 250 square meters $\left(\mathrm{m}^{2}\right)$.

- Approach-Couple individual producers and regional water-resource managers who use geospatial 
information from markets and natural systems to aid in maximizing agricultural production and sustaining potable groundwater.

- An MRLI archive provides a baseline for analysis.

- A statistical model is estimated for time-dependent nitrate accumulation.

- A production efficiency model is applied in a regulatory decision.

- Estimated the VOI of MRLI as an input to revising regional land use in 35 Iowa counties and 2 aquifers for production of corn and soybeans and sustaining groundwater quality.

- $\$ 43$ million VOI for a 1-percent improvement in information.

This example case study has been completed with an estimate of the VOI. The other two are under development.

\section{Case Study 2}

- Application of an earthquake scenario (USGS: The Great Shake Out): Spatiotemporal natural science process models provide input for estimating earthquake housing risk concentration and mitigation.

- Study highlights social inequality issues.

- Approach-Couple an individual's housing and income status and regional earthquake hazards to help minimize housing damage and sustaining economic production and growth.

- Geospatial information provides a baseline for analysis, and natural science process models provide a scenario.

- A spatial risk indicator is estimated that combines housing damage and low-income group concentration by census tract.

- A benefit-cost analysis is applied in for mitigation of the earthquake hazard as a building regulation with and without a socioeconomic variable.

- The expanded regulation includes a socioeconomic criterion that uses geospatial information to identify how many low-income multifamily buildings are affected.

- The study demonstrates the cost effectiveness of adding socioeconomic criteria to assess the social justice issue.

- Benefits are estimated for a retrofit building code based on mitigation efficiency and income status in Los Angeles County, California.

\section{Case Study 3}

- The third example is a proposed joint public ("general" information) - private ("specific" information) application to assess how geospatial information can be used to reduce environmental externalities in ecosystem services markets.

- The application is to examine how remotely-sensed data can reduce the transactions and enforcement costs of a cap-and-trade market.

- This research would use the Philadelphia region as an example.

- Moderate-resolution imagery is used with World View 3 data to support market operations by monitoring investments on a regular basis.

In summary, digital geospatial data are a technological innovation. Investments in the technologies that deliver geospatial data have economic benefits. Microeconomic analysis can be used in specific applications to quantify the VOI of geospatial information.

\section{David Arthurs}

Economics is not about money, but instead, is a structure with which to view the world and make decisions about social interactions. Economic assessments are supposed to provide a "rational" foundation for policy decisions. Policy decisions are also influenced by "politics"- the exogenous factors that are not "rational." How can economic assessment operate in this environment? Decision criteria - a lot of people and points of view are represented, underlying real factors (see the production possibility frontier). There is no right answer, but rather, infinite possibilities. There are many challenges in performing economic assessments. Methods are adequate: do not make the analysis too complex; it is difficult to move from micro ("value in use") to macro (value in the economy). Regarding data, there are limitations in the ability of users to articulate value; the structure of economic statistics agency data can be challenging, and there are restrictions on the collection of data. Finally, there is a lack of common understanding and language. Collective mitigation actions include the following: using accepted approaches to economic assessment; creating a database of example studies and benefits transfer (for example, Environmental Valuation Reference Inventory); and community review and accreditation of studies.

\section{Ben Simon}

The techniques presented in this paper are grounded in traditional welfare economics. Distribution of income is implied by a production possibilities frontier. The paper presents three well-documented case studies. Markets need information to function; more information should imply more efficient markets. Asymmetries are endemic, and remote sensing can help in a lot of ways. In relation to ecosystems service markets, remote sensing is valuable, but we need to 
figure out what the corresponding market rules are. Obtaining information is not costless, and there should be some recognition of the cost. The analysis provided in this paper helps illustrate tradeoffs and the contribution of economics to the measurement process. Future research using techniques that validate estimates similar to the ones made in this paper would be valuable.

\section{Larry Sugarbaker}

Larry thinks of himself as a practitioner but has been on the tip of the spear for his entire career. He appreciated the three case studies provided and looked at a more simplified way of how we evaluate the tradeoff between societal services and production. Real business cases have been used in the USGS and Larry discussed, as examples, USGS work on light detection and ranging (lidar). User-based requirement assessments were performed, leading to benefits that might be achieved.

Challenge - The collective public value of open data is contrary to the investment model of Government agencies in which mission needs drive data collection. How will open data influence the investment model if the data collectors are mission focused? How can this be changed, or does it need to be changed? Larry gave the example of FEMA flood maps, which were originally created to meet only their mission needs and are now being used more broadly.

\section{Carl Shapiro and Richard Bernknopf}

Why are we bothering with the value of information? Certain types of information are multipurpose and support multiple stakeholders. These types of information fit the criteria of a public good, so techniques from resource and environmental economics are particularly useful. The USGS tries to provide unbiased information. Positive analysis can be tested for right or wrong. Normative analysis takes into account and incorporates values. What we are talking about here is positive analysis. How do we start obtaining this information at less cost and time? Not every type of information needs to be valued. Some information is very costly and requires more knowledge about its socioeconomic impact. Equity and fairness issues exist and need to be considered. The production possibilities frontier approach shows efficiency but does not address equity. One of the challenges that economists face in the value of information is the issue of trust and believability. This model is appropriate because it represents a number and narrative, and explains why the benefits are occurring. Presenting just a number reduces the believability.

Rich mentioned the limitations of the production possibility frontier approach and suggested using a portfolio approach for comparing options for decisions.

\section{Discussion}

It is good to use multiple methods to achieve confidence in the results. The introductory position paper by Alan Smart, which summarizes methods, was noted.
There is a general consensus that studies give decisionmakers a different data view; however, this use of information may not be cost effective or practical because of the length of the studies. The information in studies could end up being far more confusing to a decisionmaker than helpful, even if it was possible to apply the information in a timely manner. There is a balance that needs to be struck. How do we actually make information about socioeconomic impacts useful to policy makers?

Geospatial information, in general, leverages a vast amount of non-market goods and services. We need to think about the economic value of the information, to make others appreciate why we make these investments. This is not about the data, but rather, the attributes of the data. Do we need data in another spectral resolution scale, or at a finer scale? This question is important to consider for future investments and infrastructure. Most important are the attributes to leverage how we manage our resources. We try to minimize how many observations are needed to get a certain level of uncertainty reduced. In the case of satellites, how many times do I need to see the satellite data to determine what color the observation really is?

\section{Session 4. Emerging Issues for Societal Impact Assessments}

Chair: Alan Smart, ACIL Allen Consulting, Australia Position paper: Bridgette Wessels, University of Sheffield, U.K.; Max Craglia, EC-JRC

Panel discussants: Craig Broadbent, Illinois Wesleyan University; Philip Stark, U.C. Berkeley; John King, University of Michigan (fig. 16)

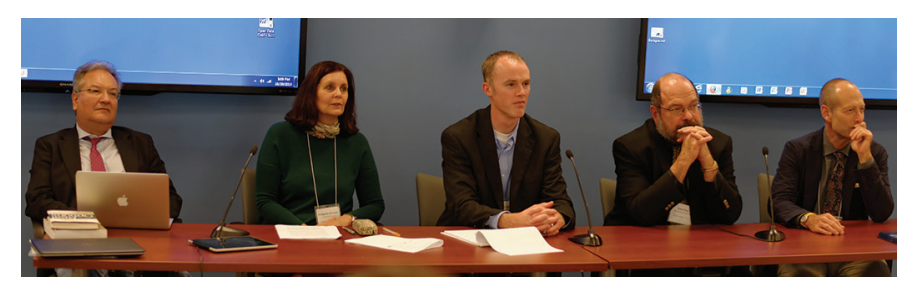

Figure 16. Session 4 panel discusses the changing role of data in society. Shown from left to right: Max Craglia, Bridgette Wessels, Craig Broadbent, John King, and Philip Stark.

\section{Bridgette Wessels}

The purpose of this position paper is to address the changing role of data in society (including geospatial data) and its possible social impacts (fig. 17). It places the debates from the earlier positioning in a social context. The presentation focused on a sustainable society and social quality, smart innovation, and data in context. To do this, Bridgette asked about the role of data and addressed some of the details about the production and use of data by societal stakeholders (individuals, governments, the commercial 


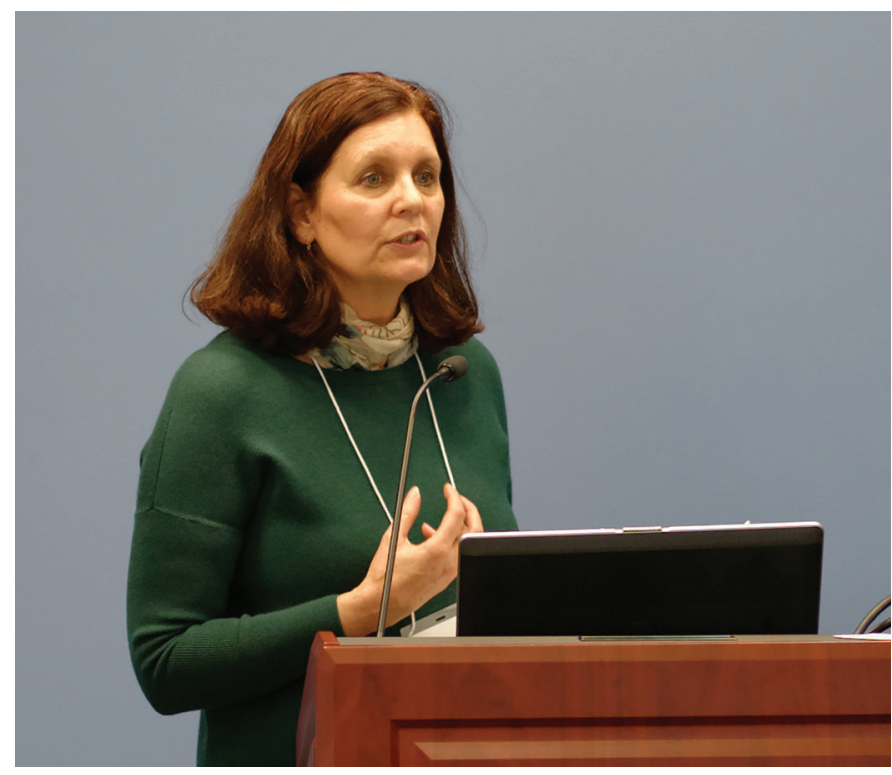

Figure 17. Bridgette Wessels presents the position paper on emerging issues for societal impact assessment.

sector, and nongovernmental organizations). The context of the discussion was the "worst financial, economic and social crisis in post war history" (Stiglitz and others, 2009). This leads us to the concepts of social quality and how we innovate in that environment (smart innovation). Challenges in part from globalization are inequality, unemployment, urbanization, waste, and environmental degradation. There is also a digital divide or data divide in the world, like access to data or to the Internet. The concept of social quality was developed in the early 1990s as some addressed the concerns about the limitations of gross domestic product (GDP) and other economic indicators to measure societal well-being. Social quality is the measure of well-being under a social environment in how much it allows people to grow and reach their potential. Well-being is multidimensional and requires environmental and geospatial data. Smart innovation includes rethinking risks and rewards, and data play a role in these dynamics. The availability of open data is uneven and fragmented across the world and results in some countries falling behind. If the data are not discoverable, their full use is not possible. There is tremendous value in the private sector in Big Data and analytics. Many governments ask, "What can we say with these data in terms of the public policy sphere?" We can maximize social and economic value through open and mobile services (connect, communicate, and challenge: Generation C). We can affect decentralized knowledge exchange. The European Commission sees the value of consumer data in terms of commercial services and helps with their inclusion. There is a lack of clarity about what the citizens can give, and what public services can provide. Are services sufficiently inclusive? Social quality indicators address values associated with environment, socioeconomic security, social cohesion, and inclusion. There is a risk of a digital divide in all dimensions. There is a real need for regulations to protect and enable innovation. We need to ask how geospatial data can be fed into social quality indicators. The paper argued that there is a requirement to develop a range of indicators that can assess and measure the social impact of open data.

\section{John King}

John King liked the position paper but felt he needed to challenge the phrase, "If you can't measure it, you can't manage it." All measurements look backwards to make predictions about the future. The Internet has led to a reversal in terms of how we think about our personal data. Four reversals (changes) have been identified, as a result of information technology:

1. Thomas Fuller: Fool's names and fool's faces are often seen in public places-Facebook now has everybody!

2. Henry Ford: Production engineering and the "supply chain"-we are switching toward a demand chain;

3. James Carey: Communication is dependent on transportation - this is now flipped as well; and

4. Margaret Thatcher: Society doesn't exist—now, really?

Walmart thinks of inventory in terms of flow instead of stock, which is why they were ready for Hurricane Katrina. Privacy and confidentiality have changed. Those who see public good as an oxymoron are not buying it. Some people think that public good is an aggregation of individual welfare; John disagrees with that line of thinking.

\section{Philip Stark}

Philip Stark showed an example of geospatial information serving the public good: mapping wild foods in "urban food deserts." Urban food deserts are defined using geospatial data: they are urban areas with low income according to the U.S. Census Bureau, more than a mile from any store that sells fresh food. His project shows that in many urban food deserts, there is in fact an abundant source of free, fresh, nutritious food, namely, edible "volunteer" plants. The Berkeley Open Source Food project is using crowdsourced science and an open-source GPS-enabled mapping tool, iNaturalist, to produce open maps of the abundance of wild edibles, many of which are invasive species (for example, dandelion, dock, oxalis, sow thistle, and so forth). Such edible "weeds" can provide fiber and micronutrients that are missing from many U.S. diets, an absence that may contribute to the high incidence of type 2 diabetes among people who live in food deserts. These sustainable, nutritious, drought-tolerant plants already grow in neighborhoods where they are needed, but they are not recognized by residents as food; what is missing is information. Educating residents could improve their nutrition, and possibly their health, for free. 


\section{Craig Broadbent}

Craig Broadbent is an environmental economist who looks at the issues through a water-resource lens. It is expensive to clean up and share data; in addition, there is the issue of privacy. A lot of work focuses on third-party effects. Craig showed geospatial information for the Rio Grande. He discussed the difference between point source pollution, which can be traced to a single source, and non-point source pollution, which cannot directly be traced to a single source. Ethanol subsidies led to more production of corn, which in turn can lead to more nitrogen pollution in the water. Mitigation techniques for nitrogen exist, for example, no tillage, strip tillage, riparian buffers, grassed waterways (buffer zone between crops), and wetlands. Most popular are the techniques of no tillage, strip tillage, and grassed waterways. Geospatial information is important to help monitor nitrogen effects in water. The challenge comes in integrating different data sources because it is hard to overlay data in geospatial maps from multiple data sources.

\section{Discussion}

The examples given in responses show innovative uses of data, incorporation of local knowledge, and use of data leading to social equality.

\section{Workshop Recommendations and Summary}

Chair: Max Craglia, EC-JRC

Panel Discussants: Lawrence Friedl, NASA; Jamie Kruse, East Carolina University (fig. 18)

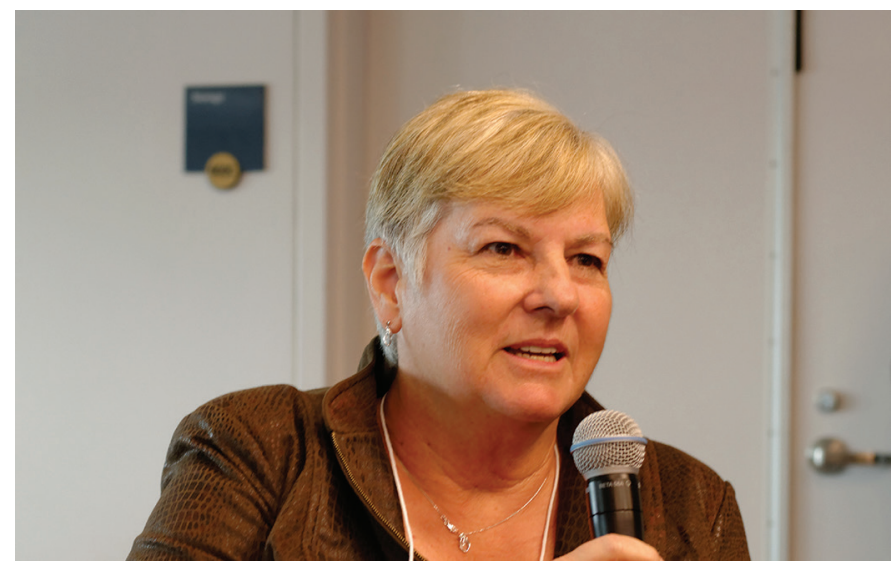

Figure 18. Jamie Kruse draws lessons learned from the workshop.

\section{Jamie Kruse}

Where is next? In this area, we are awash in innovation and entrepreneurship. We are in the "wild west" at this point in time with digital information. There are existing methods for valuing geospatial data that need to be refined. What about the applications that we have not imagined yet? How do we value future opportunities?

What is the role of Government here? In the case of "public good" geospatial data sources, the Government will be charged with providing unbiased information. The Government is a data interpreter, and the data need to be provided with the utmost scientific integrity. The Government has a regulatory and risk management role. National and private security needs to be protected. Private industry can create and interpret data. Who is going to do it and why? We must look at the incentives behind actions. There must be an incentive, either financial or social. This has to be balanced against the protection of personal rights. What do we need?

Valuing geospatial data will not be easy. New statistical methods are needed to understand large datasets. Is there a way to use geospatial and economic information to figure out what affordability means?

\section{Lawrence Friedl}

Two items resonated: participation during the ideageneration phase and feedback from the public. Public-private partnerships could be used to address budget realities and to leverage strengths. We need to engage with nontraditional partners to address key challenges.

How do we address the need to foster better interactions between involved communities? There is an interest to connect with social sciences. Help is needed to answer the question, "What does that mean?"

Data becomes more valuable as it is used to make better decisions. There was discussion of a need for case studies. Connecting projects with managers interested in participating with these studies is important. How do we know when we are being effective and what is valuable? What is important for the problem at hand? The landscape is evolving so rapidly that the regulatory framework and policy framework operate at different speeds than the environment.

How do we recognize success? Has this issue been addressed in the past? We need a framework to evaluate future work (fig. 19). What are the metrics? What are the measures of progress (rather than success)? More agreement on methodologies would be useful. It is important to talk to decisionmakers and ask what they need. National security geospatial databases should not be ignored, as some cleared researchers may extract

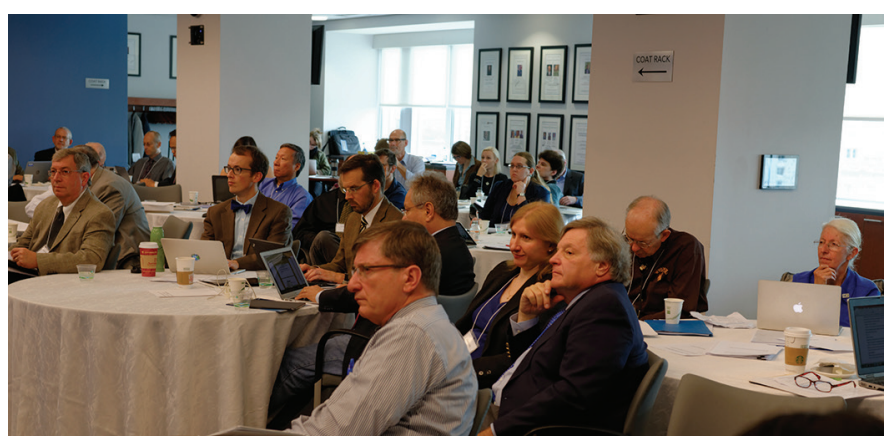

Figure 19. Attendees consider the paths forward. 
information. Private-sector databases should not be ignored either. The decadal survey for Earth science will be available from the national academies within 2 years. What does this group want to put forward?

\section{End of Day 2}

\section{References Cited}

Beagrie, N., Chruszcz, J. and Lavoie, B., 2008, Keeping research data safe: London and Bristol, Jisc, accessed February 17, 2016, at http://www.beagrie.com/krds.php.

Beagrie, N., Lavoie, B., and Wollard, M., 2010, Keeping research data safe 2: London and Bristol, Jisc, accessed February 17, 2016, at http://www.beagrie.com/jisc.php.

Beagrie, N., and Houghton, J.W., 2013a, The value and impact of the archaeology data services-A study and methods for enhancing sustainability: Bristol and London, Joint Information Systems Committee, accessed February 17, 2016, at http://www.jisc.ac.uk/whatwedo/programmes/preservation/ADSImpact.aspx.

Beagrie, N., and Houghton, J.W., 2013b, The value and impact of the British Atmospheric Data Centre: Bristol and London, Joint Information Systems Committee and the Natural Environment Research Council, U.K., accessed February 17, 2016, at http://www.jisc.ac.uk/whatwedo/ programmes/di_directions/strategicdirections/badc.aspx.

Beagrie, N., and Houghton, J.W., 2014, The value and impact of data sharing and curation: A synthesis of three recent studies of UK Research Data Centres, Bristol and London, Joint Information Systems Committee (Jisc), accessed February 17, 2016, at http://repository.jisc.ac.uk/5568/.

BrightPoint Consulting, Inc., 2012, Political influence: BrightPoint Web site, accessed February 17, 2016, at http://www.brightpointinc.com/political_influence/.

Cabinet Office, 2013, G8 open data charter and technical annex, June 2013: Report accessed February 18, 2016, at https://www.gov.uk/government/publications/open-datacharter.

Chui, Michael, Manyika, James, Bughin, Jacques, Dobbs, Richard, Roxburgh, Charles, Sarrazin, Hugo, Sands, Geoffrey, and Westergren, Magdalena, 2012, The social economy-Unlocking value and productivity through social technologies: McKinsey Global Institute Report, accessed February 17, 2016, at http://www.mckinsey.com/insights/ high_tech_telecoms_internet/the_social_economy.
DotEcon, 2006, The commercial use of public information (CUPI): London, Office of Fair Trading Report OFT861, accessed February 17, 2016, at http:/www.opsi.gov.uk/ advice/poi/oft-cupi.pdf.

Executive Office of the President National Science and Technology Council, 2013, National Strategy for Civil Earth Observations: Executive Office of the President National Science and Technology Council report, accessed March 3, 2016, at, http://www.whitehouse.gov/sites/default/ files/microsites/ostp/nstc_2013_earthobsstrategy.pdf.

Funtowicz, S.O., and Ravetz, J.R., 1993, Science for the postnormal age: Futures, v. 25, no. 7, p. 739-755.

Geogig.org, n.d., GeoGig: A tool for geospatial data management: Accessed February 17, 2016, at http://geogig.org/.

Google, Inc., n.d., Flu Trends, 2014: Accessed February 18 2016, http://www.google.org/flutrends/about/.

Houghton, J.W., 2011, Costs and benefits of data provision: Canberra, Report to the Australian National Data Service, accessed February 17, 2016, at http://ands.org.au/resource/ cost-benefit.html.

Houghton, J.W., Swan, A., and Brown, S., 2011, Access to research and technical information in Denmark, Forsknings- og Innovationsstyrelsen and DEFF: Report to The Danish Agency for Science, Technology and Innovation (FI) and Denmark's Electronic Research Library (DEFF), accessed February 17, 2016, at http://fivu.dk/ en/publications/2011/access-to-research-and-technicalinformation-in-denmark.

International Federation of Surveyors (FIG) and World Bank, 2014, Fit-for-purpose land administration (2d ed): Copenhagen, Denmark, International Federation of Surveyors Publication No. 60., accessed March 3, 2016, at http://www.fig.net/resources/publications/figpub/pub60/ figpub60.asp.

Monga, Vipal, 2014, The big mystery-What's Big Data really worth?: The Wall Street Journal, October 12, 2014. [Also available at http://www.wsj.com/articles/whats-all-that-dataworth-1413157156.]

National Science and Technology Council Executive Office of the President, 2014, National Plan for Civil Earth Observations: Washington D.C., report prepared by the National Science and Technology Council Executive Office of the President, accessed February 17, 2016, at http://www.whitehouse.gov/sites/default/files/microsites/ ostp/NSTC/national_plan_for_civil_earth_observations_-july_2014.pdf. 


\section{Assessing the Socioeconomic Impact and Value of Open Geospatial Information}

PIRA, 2000, Commercial exploitation of Europe's public sector information: European Commission, Brussels, accessed February 17, 2016, at ftp://ftp.cordis.europa.eu/ pub/econtent/docs/2000_1558_en.pdf.

SINTEF, n.d., About us: SINTEF Web site, accessed March 3, 2016, at http://www.sintef.no/home/about-us/\#/.

Stiglitz, J.E., Sen, A., and Fitoussi, J.P., 2009, Report by the Commission on the Measurement of Economic Performances and Social Progress, INSEE: Accessed February 17, 2016, at http://www.insee.fr/fr/publicationset-services/dossiers web/stiglitz/doc-commission/RAPPORT_anglais.pdf.

U.S. Department of State, 2012, Digital governmentBuilding a 21st Century platform to better serve the American people: U.S. Department of State report, accessed February 18, 2016 at https://www.dhs.gov/sites/default/ files/publications/digital-strategy/digital-governmentstrategy.pdf.

Wessels, Bridgette, 2007, Inside the digital revolutionPolicing and changing communication with the public: Ashgate Publishing Company, 160 p.
Wessels, Bridgette, 2010a, The cultural dynamics of the innovation of new media-A case of telematics: VDM Verlag Dr. Muller, 324 p.

Wessels, Bridgette, 2010b, Understanding the Internet-A socio-cultural perspective: U.K., Palgrave Macmillan, $208 \mathrm{p}$.

Wessels, Bridgette, 2014, Exploring social change-Process and context: U.K., Palgrave Macmillan, 256 p.

Wessels, Bridgette, and Bagnall, Val, 2002, Information and joining up services - The case of an information guide for parents of disabled children: U.K., Policy Press at the University of Bristol, $88 \mathrm{p}$.

Wouthers, Paul, Beaulieu, Anne, Scharnhorst, Andrea, and Wyatt, Sally, eds., 2013, Virtual knowledgeExperimenting in the Humanities and the Social Science: Cambridge, Mass., MIT Press, 272 p. 


\section{Appendixes}

Appendix 1. Agenda

Appendix 2. List of Participants

Appendix 3. Brief Biography of the Speakers, Session Chairs, and Discussants 


\section{Assessing the Socioeconomic Impact and Value of Open Geospatial Information}

\section{Appendix 1. Agenda}

\begin{tabular}{|c|c|c|}
\hline \multicolumn{3}{|c|}{ Tuesday October 28, 2014} \\
\hline $8: 30-9: 00$ & Welcome/Badging_-Coffee and Tea & \\
\hline Workshop opening & Opening Session & $\begin{array}{l}\text { Chair-Molly Macauley, Resources for the } \\
\text { Future (RFF) }\end{array}$ \\
\hline $9: 00-9: 30$ & $\begin{array}{l}\text { Keynote-Open geospatial information: } \\
\text { Empowering decisions and the economy }\end{array}$ & $\begin{array}{l}\text { Suzette Kimball, Acting Director, U.S. Geo- } \\
\text { logical Survey (USGS) }\end{array}$ \\
\hline $9: 30-10: 00$ & $\begin{array}{l}\text { Keynote-The emerging information environ- } \\
\text { ment and impacts on decisionmaking }\end{array}$ & $\begin{array}{l}\text { Nick Sinai, White House Office of Science and } \\
\text { Technology Policy (OSTP) }\end{array}$ \\
\hline $10: 00-10: 30$ & $\begin{array}{l}\text { Keynote-Future evolution of geospatial } \\
\text { information sector }\end{array}$ & Walter Scott, DigitalGlobe \\
\hline $10: 30-11: 00$ & Break-Coffee and Tea & \\
\hline $11: 00-13: 00$ & $\begin{array}{l}\text { Session } 1 \text { - Impact of increased access to data } \\
\text { and new modes of consumption }\end{array}$ & $\begin{array}{l}\text { Chair-Andrew Coote, ConsultingWhere, } \\
\text { U.K.; } \\
\text { Position paper-John Houghton, Centre for } \\
\text { Strategic Economic Studies, Victoria Univer- } \\
\text { sity, Melbourne, Australia } \\
\text { Panel discussants - Pierre Glynn, USGS; Chris } \\
\text { Goranson, Department of Interior (DOI); } \\
\text { Sally Wyatt, Royal Netherland Academy of } \\
\text { Arts and Sciences }\end{array}$ \\
\hline $13: 00-14: 00$ & Lunch & Birds of a Feather lunch session \\
\hline $14: 00-16: 00$ & $\begin{array}{l}\text { Session } 2 \text { - Increased supply of geospatial } \\
\text { information and expanded participatory } \\
\text { processes in the production of data (such as } \\
\text { crowdsourcing) }\end{array}$ & $\begin{array}{l}\text { Chair-Carl Shapiro, USGS; } \\
\text { Position paper-Lea Shanley, Presidential In- } \\
\text { novation Fellow at the National Aeronautics } \\
\text { and Space Administration } \\
\text { (NASA), and University of Wisconsin-Mad- } \\
\text { ison; Max Craglia, European Commission- } \\
\text { Joint Research Centre (EC-JRC) } \\
\text { Panel discussants-Mikel Maron, Humanitar- } \\
\text { ian OpenStreetMap Team; Robin McLaren, } \\
\text { Know Edge Ltd., U.K. }\end{array}$ \\
\hline $16: 00-16: 30$ & Break & \\
\hline $16: 30-17: 30$ & Perspectives & $\begin{array}{l}\text { Chair-Jay Pearlman, J\&F Enterprise, and } \\
\text { University of Colorado; } \\
\text { Panel discussants-Molly Macauley, RFF; Jim } \\
\text { Geringer, Esri }\end{array}$ \\
\hline $17: 30-19: 00$ & Reception (sponsored by IEEE-USA) & \\
\hline
\end{tabular}




\section{Appendix 1. Agenda-Continued}

\begin{tabular}{|c|c|c|}
\hline \multicolumn{3}{|c|}{ Wednesday October 29, 2014} \\
\hline $8: 00-8: 30$ & Badging - Coffee and Tea & \\
\hline & Day 2 Opening & $\begin{array}{l}\text { Chair_Jay Pearlman, J\&F Enterprise and } \\
\text { University of Colorado }\end{array}$ \\
\hline $8: 30-8: 45$ & Welcome to Day 2 & Tim Stryker, OSTP \\
\hline $8: 45-9: 00$ & Day 1 Summary & Lawrence Friedl, NASA \\
\hline $9: 00-9: 30$ & $\begin{array}{l}\text { Keynote-Societal impact of information } \\
\text { abundance }\end{array}$ & Myron Gutmann, University of Colorado \\
\hline $9: 30-10: 00$ & $\begin{array}{l}\text { An interactive discussion on data impacts on } \\
\text { decisionmakingn }\end{array}$ & $\begin{array}{l}\text { Camille Touton, DOI; Bob O'Connor, National } \\
\text { Science Foundation (NSF); Al McGartland, } \\
\text { U.S. Environmental Protection Agency } \\
\text { (EPA) }\end{array}$ \\
\hline $10: 00-10: 30$ & Break-Coffee and Tea & \\
\hline $10: 30-12: 30$ & $\begin{array}{l}\text { Session 3-Emerging approaches for Eco- } \\
\text { nomic impact assessments }\end{array}$ & $\begin{array}{l}\text { Chair-Claire Jolly, Organisation for Economic } \\
\text { Co-operation and Development (OECD); } \\
\text { Position paper-Richard Bernknopf, University } \\
\text { of New Mexico, and Carl Shapiro, USGS } \\
\text { Panel discussants-David Arthurs, Hickling } \\
\text { Arthurs Low, Canada; Benjamin Simon, } \\
\text { DOI; Larry Sugarbaker, USGS }\end{array}$ \\
\hline $12: 30-13: 15$ & Lunch & Birds of a Feather lunch session \\
\hline $13: 15-15: 15$ & $\begin{array}{l}\text { Session 4-Emerging issues for societal } \\
\text { impact assessments }\end{array}$ & $\begin{array}{l}\text { Chair-Alan Smart, ACIL Allen Consulting, } \\
\text { Australia; } \\
\text { Position paper-Bridgette Wessels, University } \\
\text { of Sheffield, U.K.; Max Craglia, EC-JRC } \\
\text { Panel Discussants_-Craig Broadbent, Illinois } \\
\text { Wesleyan University; Philip Stark, U.C. } \\
\text { Berkeley; John King, University of Michigan }\end{array}$ \\
\hline $15: 15-16: 00$ & Workshop recommendations and summary & $\begin{array}{l}\text { Chair-Max Craglia, EC-JRC } \\
\text { Panel discussants-Lawrence Friedl, NASA; } \\
\text { Jamie Kruse, East Carolina University }\end{array}$ \\
\hline
\end{tabular}




\section{Appendix 2. List of Participants}

Joan Aron, Semantic Community, U.S.A.

David Arthurs, Hickling Arthurs Low, Canada

Jeff Atkins, National Oceanic and Atmospheric Administration (NOAA), U.S.A.

Rich Bernknopf, University of New Mexico, U.S.A.

Mark Brender, DigitalGlobe Foundation, U.S.A.

Craig Broadbent, Illinois Wesleyan University, U.S.A.

Ken Chomitz, World Bank, U.S.A.

Andrew Coote, ConsultingWhere, U.K.

Max Craglia, Joint Research Center, European Commission

Georgina Crepps, National Aeronautics and Space Administration (NASA), U.S.A.

Bradley Dorn, National Aeronautics and Space Administration (NASA), U.S.A.

Cheryl Eavey, National Science Foundation (NSF), U.S.A.

Carolyn Fonseca, National Aeronautics and Space Administration (NASA), U.S.A.

Lawrence Friedl, National Aeronautics and Space Administration (NASA), U.S.A.

Jason Gallo, Institute for Defense Analysis (IDA) Science and Technology Policy Institute (STPI), U.S.A.

Jim Geringer, Environmental Systems Research Institute (Esri), U.S.A.

Anita Gibson, Organisation for Economic Co-operation and Development (OECD), U.S.A.

Pierre Glynn, U.S. Geological Survey (USGS), U.S.A.

Chris Goranson, Presidential Innovation Fellow-Department of Interior (DOI), U.S.A.

Myron Gutmann, University of Colorado, Boulder, U.S.A.

Elisabeth Haggquist, Luleå University of Technology,

Sweden

Henry Hertzfeld, George Washington University, U.S.A.

John Houghton, Center for Strategic Economic Studies, Victoria University, Melbourne, Australia

Thorhildur Jetzek, Copenhagen Business School, Denmark

Claire Jolly, Organisation for Economic Co-operation and Development (OECD), U.S.A.

Ralph Kahn, National Aeronautics and Space Administration (NASA), U.S.A.

Suzette Kimball, U.S. Geological Survey (USGS), U.S.A.
John King, University of Michigan, U.S.A.

Jamie Kruse, East Carolina University, U.S.A.

Mary Ann Kutny, National Oceanic and Atmospheric Administration (NOAA), U.S.A.

Tony Lavoi, National Oceanic and Atmospheric Administration (NOAA), U.S.A.

Rodney Liesveld, National Aeronautics and Space Administration (NASA), U.S.A.

Sophia Liu, United States Geological Survey (USGS), U.S.A.

Lucia Lovison, Afriterra Foundation, U.S.A.

Molly Macauley, Resources for the Future, U.S.A.

Alexander MacDonald, National Aeronautics and Space Administration (NASA)

Mikel Maron, Presidential Innovation Fellow, Department of State and Humanitarian Open StreetMapTeam, U.S.A.

Al McGartland, U.S. Environmental Protection Agency (EPA), U.S.A.

Robin McLaren, Know Edge Ltd., U.K.

Larry Meinert, U.S. Geological Survey (USGS), U.S.A.

Josh Murphy, National Oceanic and Atmospheric Administration (NOAA), U.S.A.

Siobhan Murray, World Bank, U.S.A.

Bob O'Connor, National Science Foundation (NSF), U.S.A.

Francoise Pearlman, J\&F Enterprise, U.S.A.

Jay Pearlman, J\&F Enterprise, U.S.A.

Emily Pindilli, U.S. Geological Survey (USGS), U.S.A.

Ana Prados, National Aeronautics and Space Administration (NASA), U.S.A.

Tracy Rouleau, National Oceanic and Atmospheric Administration (NOAA), U.S.A.

Walter Scott, DigitalGlobe, U.S.A.

Nancy Searby, National Aeronautics and Space Administration (NASA), U.S.A.

Lea Shanley, Presidential Innovation Fellow at National Aeronautics and Space Administration (NASA), and University of Wisconsin-Madison, U.S.A.

Carl Shapiro, U.S. Geological Survey (USGS), U.S.A.

Benjamin Simon, Department of the Interior (DOI), U.S.A.

Nick Sinai, Office of Science and Technology Policy (OSTP), U.S.A. 
Alan Smart, ACIL Allen Consulting, Australia

Philip Stark, University of California, Berkley, U.S.A.

Tim Stryker, Office of Science and Technology Policy (OSTP), U.S.A.

Larry Sugarbaker, U.S. Geological Survey (USGS), U.S.A.

Camille Touton, Department of the Interior (DOI), U.S.A.

Andrew Turner, Esri, U.S.A.

Glenn Vancauwenberghe, Spatial Applications Division Leuven, KU Leuven, Belgium

Bridgette Wessels, Sheffield University, U.K.

Curtis Wong, Microsoft, U.S.A.
Chuck Wooldridge, National Oceanic and Atmospheric Administration (NOAA), U.S.A.

Sally Wyatt, Royal Netherlands Academy of Arts and Sciences, The Netherlands

Karen Yasumura, DigitalGlobe, U.S.A.

Jonghyun Yoon, World Bank, U.S.A.

Paul Young, U.S. Geological Survey (USGS), U.S.A. 


\section{Appendix 3. Brief Biography of the Speakers, Session Chairs, and Discussants}

\section{David Arthurs}

David Arthurs is the president of Hickling Arthurs Low Corporation (HAL). He specializes in economic analysis, policy development, and strategic planning for public sector science and technology organizations. For the past 15 years, David has been informing the evolution of all aspects of the Canadian geomatics industry, including surveying, geodesy, Earth observation, cartography, hydrography, positioning, and geographic information systems. HAL is currently finalizing a major study for Natural Resources Canada on the economic value of geospatial information in the Canadian economy.

David has a B.S. degree in engineering from the University of Waterloo, an M.B.A. degree from the University of Ottawa, and a Ph.D. from the School of Business at Queens University.

HAL is headquartered in Ottawa, Canada. Clients are decisionmakers, policy advisors and public sector administrators at the local, regional, and national levels, who seek specialized information, strategies, and assessments that are factual, practical, and that can catalyze change. HAL's practice areas include innovation policy, public administration and strategy, socioeconomic impact analysis, and regional economic development.

\section{Richard L. Bernknopf}

Richard L. Bernknopf is a research professor in the Department of Economics at the University of New Mexico (UNM). Before joining the faculty at UNM, Richard was an economist with the U.S. Geological Survey (USGS) for more than 38 years. His research focuses on the demonstration of the relevance (value to society) of natural science information, including Earth observation and the translation of that information into a form compatible with decisionmaking processes. During his tenure at the USGS, Richard was a consulting professor and co-director of the Center for Earth Science Information Research at Stanford University, and co-director of the Spatial Integration Laboratory for Urban Systems at the University of Pennsylvania. Currently, Richard is associated with the Science Impact Laboratory for Policy and Economics at the University of New Mexico and the Wharton Geospatial Initiative at the University of Pennsylvania.

\section{Craig D. Broadbent}

Craig D. Broadbent is an assistant professor of economics at Illinois Wesleyan University in Bloomington, Illinois. Craig received his Ph.D. in environmental and resource economics with an emphasis in public finance and experimental economics in 2009. His dissertation work emphasized the importance of coupling physical and engineering models with an economic market model that could facilitate the voluntary transfer of water rights on a temporary basis. Craig has published papers on these temporary transfer markets in
Agricultural Water Management, the Journal of Contemporary Water Research \& Education, and the Natural Resources Journal. Currently, he is part of a joint effort with the U.S. Geological Survey, investigating water quality markets for nitrate mitigation in the central portion of the United States. Geospatial data are a large component of this effort because they form the basis of nitrate monitoring, which involves tracking the location and quantity of nitrogen in waterways through the Mississippi River region.

In addition to investigating the potential of water markets, Craig specializes in the valuation of ecosystem services. He has been part of two studies that gather public perceptions for riparian systems in the southwestern United States. This effort has led to an investigation into the precision of nonmarket valuation techniques with multiple published papers in the Journal of Environmental Planning and Management, Economics Bulletin, and Western Economics Forum. Currently, he is coupling multiple physical and social science models together to conduct valuation studies for two river systems in southern Arizona. This research investigates the tradeoffs of water use for human consumption versus riparian ecosystem preservation. Geospatial data are utilized to create maps that depict vegetation species throughout these river systems, which are used to demonstrate possible future conditions.

\section{Andy Coote}

Andrew Coote is the director of ConsultingWhere, U.K. $\mathrm{He}$ is an information technology consultant, specializing in location-based applications, with a strong interest in strategy development and socioeconomic value assessment.

Andrew has over 30 years of experience in developing and using information systems, specializing in management of location-enabled applications. He has held senior management positions in both Government at Ordnance Survey and the private sector at Esri (U.K.). His undergraduate degree was in Land Surveying and Geography, Andrew also holds an M.Sc. degree in computer science from University College London and a diploma in company direction.

In 2008, Andrew formed ConsultingWhere, an organization that specializes in providing business strategy advice and business case development support to organizations worldwide. His recent consultancy assignments include facilitating data specification work for the European Union INSPIRE program; strategic business direction reviews for software companies in the United States, Russia, and Egypt; and advising the New Zealand Geospatial Office. He has led recent studies on the economic benefits of geospatial information for both local government and Ordnance Survey. In the latter case, this was part of their evaluation of the impact of the Open Data Initiative. 


\section{Massimo "Max" Craglia}

Since 2005 Max Craglia has been working at the Digital Earth and Reference Data Unit, European CommissionJoint Research Centre. The unit is responsible for the technical coordination of the INSPIRE Directive, creating an infrastructure for spatial information in Europe to support environmental policy. Max is responsible for research on the socioeconomic impact assessment of INSPIRE. He coordinates research projects related to the interoperability of multidisciplinary e-infrastructures that contribute to the Global Earth Observation System of Systems. Recent activities have taken Digital Earth as a framework for evolving current e-infrastructures and integrate official data with real-time data coming from citizens and sensors. This approach is being applied to develop novel indicators of quality of life in urban areas to include both quantitative data from sensors and qualitative information from the public. For a selection of recent publications, please see http://inspire-forum.jrc.ec.europa.eu/pg/pages/view/29954/ publications-articles-in-refereed-journals.

\section{Lawrence Friedl}

Lawrence Friedl serves as the Director of the Applied Sciences Program within the National Aeronautics and Space Administration (NASA) Earth Science Division. The program supports efforts to discover and demonstrate innovative and practical applications of Earth science by public and private organizations. He has been with the NASA Applied Sciences Program since 2002.

Among his responsibilities, Lawrence is a co-chair of the interagency U.S. Group on Earth Observations (USGEO) and represents the United States on the international Group on Earth Observations (GEO). Lawrence is the NASA principal for the interagency Civil Applications Committee. He also serves on the award committee for the National Space Club's Award for Innovative Uses of Earth Observation Satellite Data, the program organizing committee for the American Meteorological Society 2014 meeting, and the International Committee for Remote Sensing of Environment.

Prior to joining NASA, Lawrence worked at the U.S. Environmental Protection Agency, focusing on applications of geospatial data and technology. He also served as a space shuttle flight controller in NASA's Mission Control Center for 15 missions, including several Earth science missions.

Lawrence received a master's degree in public policy from Harvard University's Kennedy School of Government, specializing in science and technology policy. He received a bachelor's degree in mechanical \& aerospace engineering from Princeton University. Lawrence also received a certificate in space policy and law from the International Space University.

\section{Jason Gallo}

Jason Gallo leads the IDA Science and Technology Policy Institute's (STPI) Earth observation work with the Office of Science and Technology Policy (OSTP) and the National
Science and Technology Council (NSTC) U.S. Group on Earth Observation Subcommittee and Program. Before joining STPI, Jason was a lecturer in the communications studies department at Northwestern University and a dissertation fellow at the Center for Nanotechnology in Society at the University of Wisconsin-Madison. His academic research focused on the role of the National Science Foundation in the development of U.S. information infrastructure. He holds an M.A. degree in communication, culture, and technology from Georgetown University and a Ph.D. in media, technology, and society from Northwestern University.

\section{James E. "Jim" Geringer}

A native of Wyoming, James Geringer was reared on the family farm near Wheatland, and is a 10 -year member of 4-H. He holds a B.S. degree in mechanical engineering from Kansas State University. James spent several years on the U.S. Air Force (USAF) unmanned space programs, integrating space boosters and satellites for both the Air Force and the National Aeronautics and Space Administration (NASA), including the Global Positioning Satellite System, early warning systems and the Mars Viking Lander. He served in the Wyoming legislature from 1983 to 1994, including 6 years each in the House and the Senate. His full time occupations included contract administrator for the construction of a large coal-fired electric power plant, then full-time production agriculture. James was elected Wyoming's 30th Governor in 1994, and completed a second term in January 2003.

In 2003, James Geringer joined Environmental Systems Research Institute (Esri), the world leader of geographic information systems software, as a senior executive. He serves on the board of directors for Dakota Gasification, producer of synthetic natural gas and 10 other co-products. James and his wife Sherri, have 5 children, 11 grandchildren, and 1 greatgrandchild. They base their consulting business, The Geringer Group, at their home near Cheyenne, Wyoming.

Other positions include board chair, Western Governors University; National Advisory Board, University of Wyoming College of Engineering and Applied Sciences; chair, Association of Governing Boards for Universities and Colleges; Global Positioning Satellite System Advisory Board; chair, Policy Consensus Initiative, fostering collaboration between and among elected leaders; chair, Complete College America; vice-chair, DigiLEARN, promoting technology for $\mathrm{K}-12$ student-centered learning.

Past activities include chair, National Governors Association Technology Task Force; chair, Education Commission of the States; chair, Western Governors' Association; chair of the Interstate Oil and Gas Compact Commission; National Commission on Mathematics \& Science Teaching; National Commission on Service-Learning; National Commission on Teaching \& America's Future; Mapping Sciences Committee and the Climate Choices Committee under the National Research Council, National Academy of Science. 


\section{Pierre Glynn}

Pierre Glynn currently serves as branch chief for the eastern branch of the U.S. Geological Survey National Research Program in Reston, Virginia. The scientists in his branch conduct research in many fields and on many issues. These include numerical modeling of water flow and solute transport, environmental isotope forensics and characterization, groundwater dating, water and sediment contamination problems, nutrient cycling, ecological habitats, geomorphic processes, and the application of molecular and other techniques to the study of microbial processes.

Beyond his branch responsibilities, Pierre has undertaken a wide variety of assignments for the USGS. Recently, these have included the advancement of integrated environmental and ecological modeling across a range of organizations and disciplinary interests. His research efforts have focused on geochemical modeling and characterization of groundwater contamination, nuclear waste disposal, and groundwater dating studies.

Earlier in his career, Pierre also developed a thermodynamic framework to explain and predict how substitutional impurities affect the solubility and aqueous interactions of mineral phases and how impurities are released and taken up by minerals. His academic background includes a B.A. degree (with a major in geological sciences) from Columbia College and Lamont Doherty Earth Observatory, an M.Sc. degree from the University of Quebec in Montreal in isotopic environmental geochemistry and the cycling of atmospheric ${ }^{14} \mathrm{CO}_{2}$, and a Ph.D. from the University of Waterloo, where his studies focused on groundwater studies and the thermodynamics of water-rock interactions.

\section{Christopher "Chris" Goranson}

Christopher Goranson is a Presidential Innovation Fellow working to support the Department of the Interior's efforts to make data and services covering our Nation's public lands and waters more accessible. Chris has worked in the fields of design, public health, academia, Government services and planning, and most recently as the director of the Parsons Institute for Information Mapping (PIIM) at The New School. While there, his team provided innovative design support for electronic health records at the Department of Defense and Veteran's Administration, and supported the Defense Advanced Research Projects Agency (DARPA) XDATA program. Other recent efforts include climate visualization initiatives with the Parsons Institute at The New School for Design, Aalborg University, and the University of Southern California (USC) / National Aeronautics and Space Administration (NASA) Jet Propulsion Laboratory (JPL). Previously, Chris was the director of the Geographic Information Systems Center at the New York City Department of Health, and in 2008, completed a National Science Foundation (NSF)-funded fellowship to compare different disease cluster detection methods at Japan's National Institute of Public Health. Originally from Colorado, Chris is looking forward to bringing together a love of the outdoors and technology through this project.

\section{Myron Gutmann}

Myron Gutmann specializes in historical demography and population-environment relationships, with a focus on Europe and the Americas during the past four centuries. His current research focuses on the relationship between population and environment in the Great Plains of the United States, and on the history of the U.S. Hispanic population.

Myron is a professor at the Department of History, University of Colorado, Boulder; and off-campus research affiliate at the Population Studies Center, University of Michigan. He obtained his Ph.D. from Princeton University.

\section{Henry R. Hertzfeld}

Henry Hertzfeld is a research professor of space policy and international affairs at the Space Policy Institute, Center for International Science and Technology Policy, Elliott School of International Affairs, George Washington University (GWU). He is also an adjunct professor of law at GWU. Henry is an expert in the economic, legal, and policy issues of space and advanced technological development. He has served as a senior economist and policy analyst at both the National Aeronautics and Space Administration (NASA) and the National Science Foundation, and is a consultant to both United States and international agencies and organizations. Henry is author of many articles on the economic and legal issues concerning space and technology. He is a member of the bar in Pennsylvania and the District of Columbia. Henry can be contacted by e-mail at hrh@gwu.edu or hhertzfeld@ law.gwu.edu.

\section{John Houghton}

John Houghton is professorial fellow at Victoria University's Victorian Institute of Strategic Economic Studies (VISES). He has published and spoken widely on information technology, industry, and science and technology policy issues, and he has been a regular consultant to national and international agencies, including the Organization for Economic Cooperation and Development.

John's research is at the interface of theory and practice, with a strong focus on the policy application of economic and social theory. Consequently, his contribution tends to be in bringing knowledge and research methods to bear on policy issues in an effort to raise the level of policy debate and improve policy outcomes. In 1998, John was awarded a National Australia Day Council, Australia Day Medal for his contribution to industry policy development.

A major focus of John's recent research has been on knowledge access and the economic and social impacts of access to information. This work explores the economic implications of alternative publication and distribution models and the impacts of those models on the economy and society. Other major foci include open access models for scientific and scholarly publishing, the curation and open sharing of research 
data, and the costs and benefits of making public sector information and Government data more openly and freely available (see http://www.vises.org.au/projects/innovation. htm).

\section{Jerry Johnston}

Jerry Johnston is the Geospatial Information Officer at the U.S. Department of the Interior (DOI). In this role, Jerry leads efforts by DOI to coordinate and implement geospatial technology across the department to meet a wide range of mission goals. This includes providing a vision for geospatial interoperability throughout the enterprise, with particular focus on building and operating the National Geospatial Platform. Previously, he was with the U.S. Environmental Protection Agency (EPA), most recently serving as the agency's geospatial information officer. Prior to his work at the EPA, he worked at Image Matters L.L.C. of Leesburg, Virginia, and Pangaea Information Technologies of Chicago, Illinois, both providers of geospatial information management products and services. Jerry holds a B.S. degree in environmental science from Michigan State University, as well as M.S. and Ph.D. degrees in environmental science from Indiana University, Bloomington, and recently completed his term as a charter member of the National Geospatial Advisory Committee (NGAC).

\section{Claire Jolly}

Claire Jolly is head of the Organisation for Economic Co-operation and Development (OECD) Space Forum, in the OECD's Directorate for Science, Technology and Industry. Claire has 18 years of experience in business and policy analysis, having worked for both public and private organizations in aerospace and defense in Europe and North America, before joining the OECD in 2003. Her dual background is in international relations - finance (M.A., Versailles and Cornell University) and aerospace engineering (École Nationale Supérieure de Techniques Avancées [ENSTA] in Paris), with a focus on space applications (M.Sc., International Space University in Strasbourg, France). Claire is an alumna of the Institute for Higher National Defence Studies in Paris (Institut des Hautes Etudes de Défense Nationale [IHEDN]). The OECD Space Forum assists governments, space-related agencies, and the private sector to better identify the statistical contours of the space sector, while investigating the space infrastructure's economic significance, innovation role, and potential impacts for the larger economy (for example, a publication titled, "The Space Economy at a Glance"). In 2015, the Space Forum's Steering Group includes ten members, nine national space agencies / official bodies in charge of space activities from OECD economies and the European Space Agency (http://oe.cd/space forum).

\section{Suzette Kimball}

Suzette Kimball has been Director of the U.S. Geological Survey (USGS) since January 2016 and was USGS Acting Director during 2013-16. She is internationally known for her work in coastal processes and served as Deputy Director from 2010 to 2013. Suzette was named Associate Director for Geology in 2008, coming to that position from being the Director of the Eastern Region since 2004.

Suzette joined the USGS as Eastern Regional Executive for Biology. In that position, she built many partnerships, helped shape programs, and led the establishment of the USGS Florida Integrated Science Center. Suzette came to the USGS from the National Park Service in Atlanta, where she was Associate Regional Director.

She was an assistant professor of environmental sciences at the University of Virginia, co-director of the Center for Coastal Management and Policy and a marine scientist at the Virginia Institute of Marine Science, and managed coastal morphology and barrier island studies at the U.S. Army Corps of Engineers.

Suzette serves on executive boards and many State and national committees, including the Department of the Interior (DOI) Climate and Energy Task Force, the U.S. National Committee on GeoScience, the National Academy of Science Roundtable on Environmental Health, the DOI Senior Ocean Policy Team, and the International Steering Committee for OneGeology. She was on the board of directors of the Coastal Society and has served as secretary of the American Geophysical Union's Ocean Sciences Section.

She has authored numerous publications on barrier island dynamics, coastal ecosystem science, coastal-zone management and policy, and natural resource exploration, evaluation, and management. Suzette has twice received the Presidential Rank Award and twice received the Secretary of the Interior's Gold Level Award for Executive Leadership, and the Secretary of the Interior's Meritorious Service Award.

Suzette has a doctorate in environmental sciences with a specialty in coastal processes from the University of Virginia, a master's degree in geology and geophysics from Ball State University, and a bachelor's degree in English and geology from the College of William \& Mary.

\section{John King}

John Leslie King is W.W. Bishop professor of information, former dean of the School of Information, and former vice provost at the University of Michigan. He came to Michigan in 2000 after serving 20 years as a faculty member at the University of California at Irvine. John has published widely from his research on the relationship between changes in information technology and changes in organizations, institutions, and markets. He has been a Marvin Bower Fellow at the Harvard Business School, distinguished visiting professor at the National University of Singapore and at Nanyang Technological University in Singapore, and a Fulbright Distinguished Chair in American Studies at the University of Frankfurt. From 1992 to 1998, John was editor-in-chief of the INFORMS Journal Information Systems Research, and has served as associate editor for many other journals. He has been a member of the Board of the Computing Research Association (CRA), 
the Council of the Computing Community Consortium, and National Science Foundation advisory committees for Computer and Information Science and Engineering (CISE), Social, Behavioral and Economic Sciences (SBE), and Cyberinfrastructure (ACCI). John also has served on a number of National Research Council studies. John holds a Ph.D. in administration from the University of California, Irvine, and an honorary doctorate in economics from Copenhagen Business School. He is a Fellow of the Association for Information Systems and a Fellow of the American Association for the Advancement of Science.

\section{Jamie Kruse}

Jamie Kruse is recognized for her research in economics and decisionmaking under uncertainty, especially as it relates to natural hazards. She completed her doctoral work at the University of Arizona under dissertation advisor, Vernon Smith (2002 Nobel Laureate). Jamie has published over 50 refereed journal articles in addition to proceedings, abstracts, and reports. Her work has appeared in Econometrica, RAND Journal of Economics, Southern Economic Journal, Journal of Economic Behavior and Organization, Economic Inquiry, Natural Hazards Review, Journal of Wind Engineering and Industrial Aerodynamics, Environmetrics, Weather and Forecasting, Risk Analysis, Journal of Risk and Insurance, and others.

Jamie has held faculty positions at the University of Colorado, Texas Tech University, East Carolina University, and a visiting position at Eidgenossische Technische Hochschule (ETH) in Zurich, Switzerland. Her funded research has been supported by the National Science Foundation, Department of Energy, National Institute of Standards and Technology, Federal Emergency Management Agency, Federal Deposit Insurance Corporation, Niagara Mohawk, State of Texas and the State of North Carolina. Jamie has served as principal investigator (PI) or co-investigator (Co-I) of research projects totaling over $\$ 20$ million. She is serving as a mentor to the 2014-16 cohort of the National Science Foundation (NSF) Enabling the Next Generation of Hazards Researchers, having mentored the 2008-10 cohort as well.

During 2010, Jamie held the position of Chief Economist at the National Oceanic and Atmospheric Administration (NOAA). Her responsibilities within NOAA included member on the NOAA Research Council and chair of the Research Council Social Science Committee. Jamie was co-chair of the ad hoc committee for scientific integrity. At the interagency level, she served as a member of the Office of Science and Technology Policy (OSTP) Subcommittee on Social, Behavioural, and Economic Sciences, OSTP Subcommittee on Ocean Science and Technology, and was co-chair of the Ocean Social Science Interagency Working Group. On April 20, 2010, an explosion of the drilling rig known as the Deepwater Horizon triggered a response from NOAA that involved all line offices. Jamie served as lead in the social science thematic area for the NOAA Deepwater Horizon Science Team and served on the National Incident Command Economic Solutions Team.

At East Carolina University (ECU), Jamie was inducted as one of the 2011 Women of Distinction. Since then, Jamie has been recognized by ECU's Division of Research and Graduate Studies with the Lifetime Achievement Award for Research and Creative Work and honored with the HCAS Distinguished Professorship.

\section{Molly Macauley}

Molly Macauley is vice president for research and Senior Fellow with Resources for the Future (RFF), in Washington D.C. RFF was established at the request of President Truman as a think tank focusing on the economics of natural resources. Her research emphasizes new technology and its application to natural and environmental resources, including the value of satellite-derived earth science information and its use in understanding ecological systems and human relationships with these systems, and the value placed by the public on the Nation's space activities. Molly frequently testifies before Congress and serves on national level committees and panels including the Committee on Earth Science and Applications from Space of the National Research Council's Space Studies Board, the board of advisors for the Thomas Jefferson Public Policy Program at the College of William and Mary, the Science Advisory Board of the National Oceanic and Space Administration, the Earth Science Applications Advisory Group of the National Aeronautics and Space Administration (NASA), and the Scholarship Committee of the Women in Aerospace Foundation. She also served as a lead author for NASA on a synthesis and assessment report for the U.S. Climate Change Science Program on the use of Earth observations. Molly was selected as a Rising Star by the National Space Society, has been elected to membership in the International Academy of Astronautics, served as a Distinguished Visitor at the invitation of the Government of Quebec, and has received awards for her work from NASA and the Federal Aviation Administration. She has published extensively with more than 80 journal articles, books, and chapters of books. Molly has also been a visiting professor in the Department of Economics at Johns Hopkins University. She holds Ph.D. and M.A. degrees in economics from Johns Hopkins University and an undergraduate degree in economics from The College of William and Mary.

\section{Mikel Maron}

Mikel Maron is a Presidential Innovation Fellow working on crowdsourcing initiatives at the Department of State. Mikel is a programmer and geographer dedicated to community and humanitarian use of open source and open data. He has organized mapping projects in India, Palestine, Egypt, Swaziland, and elsewhere with Ground Truth Initiative, and especially their flagship effort, Map Kibera, the first open source map of the slums of Nairobi. He is a long-time contributor to OpenStreetMap (OSM); and founder and board member of the Humanitarian OpenStreetMap Team, 
having helped facilitate the OSM response to the 2010 Haiti earthquake. Mikel has served as technical lead for Moabi, a collaborative data project to monitor natural resources in DRC. He co-founded the geoweb company Mapufacture (now part of Esri), helped build the first wiki at the United Nations (WaterWiki at the United Nations Development Programme [UNDP]), and generally worked on collaborative platforms and geoweb standards.

\section{Al McGartland}

Al McGartland is the Director of the National Center for Environmental Economics (NCEE) and Lead Economist at the U.S. Environmental Protection Agency (EPA). Al is responsible for insuring that EPA regulatory analyses are of high quality and in compliance with relevant EPA guidance. $\mathrm{Al}$ also develops interdisciplinary risk and benefit assessment methods to be used in EPA regulatory analyses, including the application of economic methods to value natural resource and environmental damages. Most recently, $\mathrm{Al}$ has been focusing on the benefits of improving water quality in the Chesapeake Bay, valuing reductions in noncancer morbidity, and quantifying the benefits of reducing greenhouse gases. As the director of NCEE, $\mathrm{Al}$ advises senior policy-making officials on the economics of environmental policies and helps translate research into applied policy contexts. The NCEE issues EPA Guidelines for Preparing Economic Analyses and conducts numerous studies to assess the benefits and costs of environmental programs. The center also conducts key research on environmental economic issues. $\mathrm{Al}$ also supports numerous interagency initiatives, including projects concerning agriculture and environmental risks, as well as the environmental and economic benefits of policy reform in China.

Prior to working at the EPA, Al worked at the Office of Information and Regulatory Affairs in the Office of Management and Budget. While there, Al reviewed environmental regulations and supporting analyses. In addition, $\mathrm{Al}$ served as the economic advisor to the Chairman at the Commodity Futures Trading Commission. Al was also a vice president at Abt Associates, Inc., a public policy and economics consulting firm. $\mathrm{Al}$ received his $\mathrm{Ph} . \mathrm{D}$. in economics from the University of Maryland. He has published in several journals, including the American Economic Review; the Canadian Journal of Economics; the Journal of Environmental Management; the Northwestern Law Review; the medical journal, Lancet; and the Journal of Environmental Economics and Management. $\mathrm{Al}$ also has contributed to numerous books and reports on environmental economic issues.

\section{Robin McLaren}

Robin McLaren is currently director of Know Edge Ltd., a U.K.-based, independent management consulting company formed in 1986, specializing in the application of geospatial information and is a prominent consultant in land administration. He has been at the forefront of the geospatial information system (GIS) revolution and is recognized as an expert in spatial data infrastructures and land policy. Robin works extensively with United Nations agencies, the World Bank and European Union on land policy - land reformNational Spatial Data Infrastructures (NSDI) programs, and is on a mission to ensure that land professionals are delivering appropriate land administration services to the citizen. He was the lead consultant in formulating the U.K. Location Strategy and associated business case for the U.K. Government and was a founding member of the U.K. Location Council. Robin is an Honorary Fellow at the School of GeoSciences, University of Edinburgh, and his research interests are focused on how crowdsourcing can be used to support land administration. He has co-authored the International Federation of Surveyors FIG-World Bank publication, "Fit-For-Purpose Land Administration" (International Federation of Surveyors (FIG) and World Bank, 2014)

\section{Jay Pearlman}

Jay Pearlman was Chief Engineer of NCOC\&EM at Boeing and a Boeing Technical Fellow where he was responsible for advanced development of information systems. His interests are in oceans research and information science. Jay has a Ph.D. from the University of Washington and a B.S. degree from the California Institute of Technology. Jay is a Fellow of the Institute of Electrical and Electronics Engineers (IEEE) and was IEEE co-chair of the Group on Earth Observation (GEO) Architecture and Data Committee. $\mathrm{He}$ is currently co-owner of $\mathrm{J} \& \mathrm{~F}$ Enterprise, a small technical services company operating in the global dimension. Through $\mathrm{J} \& \mathrm{~F}$ Enterprise, he is active in advancing the analyses of socioeconomic benefits from Earth and environmental information. Jay has more than 75 publications and 25 international patents.

\section{Walter S. Scott}

As executive vice president and chief technical officer of DigitalGlobe, Walter Scott is responsible the development of space and ground systems, research and product development, and technical oversight for engineering at DigitalGlobe.

Walter founded DigitalGlobe in 1992 as WorldView Imaging Corporation, which was the first company to receive a high-resolution, commercial remote sensing license from the U.S. Government (in 1993), under the 1992 Land Remote Sensing Policy Act. WorldView became EarthWatch Incorporated in 1995. He managed the development of all of the commercial remote sensing satellites for the company. Walter secured the first-ever export license for launch of U.S.manufactured imaging spacecraft on Russian launch vehicles (Start-1 and Cosmos). The company became DigitalGlobe in 2001, and with the launch of the QuickBird-2 satellite that year, offered the world's highest resolution commercial satellite imagery. Today, DigitalGlobe operates a five-satellite imaging constellation with the best revisit and greatest capacity in the industry.

From 1986 through 1992, Walter Scott worked for Lawrence Livermore National Laboratory (LLNL) in 
Livermore, California. He began as Project Leader for Computer Aided Design Tools for the Laser Pantography Program, developing tools to aid in the design of wafer-scale integrated circuits manufactured. In 1987, Walter joined a small team, developing a concept for a highly distributed constellation of space-based interceptors for the Strategic Defense Initiative, known as "Brilliant Pebbles." In late 1987, Walter became the program leader for this effort, and was responsible for creating a series of hardware prototypes and conducting flight experiments. During 1989, Walter led the program successfully through over 20 reviews of technical feasibility, system performance, military operability, and estimated cost, resulting in the adoption of Brilliant Pebbles for the Strategic Defense Initiative Organization (SDIO) space segment in 1990. In late 1991, he was assistant associate director of the physics department and was responsible for development of new space-related programs and identification of promising technologies.

Walter holds a bachelor of arts degree in applied mathematics, magna cum laude, from Harvard College and doctorate and master of science degrees in computer science from the University of California, Berkeley. He was a visiting student for a year at Edinburgh University in Scotland.

In 2004, Walter was named Entrepreneur of the Year by Ernst \& Young for the Rocky Mountain Region in the Emerging Technology category.

Walter is a member of the National Research Council's Committee on Earth Science and Applications from Space (CESAS) and a member of the board of directors of the Open Geospatial Consortium (OGC).

\section{Lea Shanley}

Lea Shanley is a Presidential Innovation Fellow working on crowdsourcing initiatives at the National Aeronautics and Space Administration (NASA). Trained as a geospatial data scientist and policy expert, her research has focused on improving Government services and empowering communities through open and participatory innovation, new technologies and social media. Previously, Lea directed the Commons Lab of the Science and Technology Innovation Program at the Wilson Center. She is one of the chief organizers and co-founders of the Federal Community of Practice on Crowdsourcing and Citizen Science, a groundbreaking effort to enable Federal agencies to engage the public in collective problem solving. In 2009, Lea was an American Association for the Advancement of Science (AAAS) Congressional Science Fellow in the U.S. Senate, crafting legislation on satellite Earth observations, oceans, and hazards. Lea also helped launch the new Citizen Science Association and Wisconsin Geographic Information Coordination Council.

\section{Carl Shapiro}

Carl Shapiro is the Director of the U.S. Geological Survey (USGS) Science and Decisions Center (SDC) and is Senior Economist, Energy and Minerals and Environmental Health. The SDC is an interdisciplinary organization advancing the use of science in natural resource decisionmaking. The center focuses on research and applications in five science areas: ecosystem services, decision science, resilience, participatory science and innovation, and natural resource economics. The center works with partners in the Department of the Interior (DOI) and other Government agencies, universities, and nongovernmental organizations to develop methods, capacity, and institutional structures to integrate science more effectively with resource management.

Before his work with the SDC, Carl was the Principal Economist in the USGS Office of the Director, where he initiated, led, and participated in economic and interdisciplinary studies on public policy issues, resources, and natural hazards. While in the Director's Office, Carl also served as Senior Advisor to the Director and Acting Chief, Office of Strategic Planning and Analysis. Carl has received the Department of the Interior's Meritorious Service and Superior Service Awards.

Carl is an adjunct associate professor of economics in the School of Public Affairs at American University in Washington, D.C., where he has taught graduate courses in economics and public management for 20 years. Carl has received the American University Outstanding Teaching Award for Adjunct Faculty, as well as the Outstanding Teaching Award in the School of Public Affairs.

\section{Nick Sinai}

As U.S. Deputy Chief Technology Officer, Nick leads President Obama's Open Data Initiatives to liberate data to fuel innovation and economic growth. A prominent advocate and frequent speaker for open data, he has said, "Government data are a valuable asset and should be available wherever possible." Nick has also advanced the idea that Americans deserve access to their own health care (through Blue Button), energy, tax, and other personal data in machine-readable formats and has championed the White House's Green Button Initiative, a public-private effort to provide electricity customers online access to their own energy usage data.

He also leads the Open Government Initiative, charged with "creating an unprecedented level of openness in Government." Nick co-authored the second U.S. Open Government National Action Plan.

Nick also helped start and grow the Presidential Innovation Fellows program, which brings tech-savvy entrepreneurs into the Federal Government for 6-12 month "tours of duty," focusing on data innovation projects.

\footnotetext{
Alan Smart

Alan Smart is a Principal at ACIL Allen Consulting in Sydney Australia. Alan advises private and public sector clients on the economics of energy, infrastructure and geospatial markets. He heads the company's geospatial practice. Alan has been involved in the economics of geospatial and positioning systems for over 15 years, undertaking the first national review of the value of spatial information in Australia in 2008. Since that time, he has
} 
completed further assessments of geospatial information systems and services in Australia, New Zealand, and the United Kingdom. He is currently involved in similar work in Canada.

Alan's professional interests are in the use and application of geospatial and positioning systems in Government and industry and in the development of evaluation methodologies and business cases.

Alan is qualified in engineering and economics and is a certified professional engineer in Australia. He is a director of the Spatial Industries Business Association and a member of the board of the Tasmanian Economic Regulator.

\section{Philip B. Stark}

Philip B. Stark is professor and chair of the Department of Statistics, director of the Statistical Computing Facility, Senior Data Science Fellow of the Berkeley Institute for Data Science, member of the Theoretical Astrophysics Center, faculty in the Designated Emphasis in Computational Science and Engineering, and affiliated faculty of the Simons Institute for the Theory of Computing and the Berkeley Food Institute at U.C. Berkeley.

His research centers on inference problems and uncertainty quantification with applications including causal inference, climate, cosmology, earthquake forecasts, elections, endangered species, food webs, geomagnetism, geriatric hearing loss, information retrieval, Internet content filters, legislation and litigation, risk assessment, seismic structure of Sun and Earth, spectrum estimation, and urban foraging to improve nutrition in "food deserts."

Philip was a Presidential Young Investigator and he won the U.C. Berkeley Chancellor's Award for Research in the Public Interest and the John Gideon Award for Election Integrity for developing methods for auditing elections now in law in California and Colorado. Methods he developed or co-developed are part of the data pipelines of the Øersted geomagnetic satellite and the Global Oscillations Network Group. Philip has consulted for major corporations and for the U.S. Department of Justice, the Federal Trade Commission, the U.S. Department of Agriculture, the U.S. Census Bureau, the U.S. Department of Housing and Urban Development, the U.S. Department of Veterans Affairs, the California Attorney General, the California Highway Patrol, and the Illinois State Attorney. Philip has testified to the U.S. House of Representatives Subcommittee on the Census; the State of California Senate Committee on Elections, Reapportionment and Constitutional Amendments; the State of California Assembly Committee on Elections and Redistricting; and the State of California Senate Committee on Natural Resources. His curriculum vitae (CV) is available at http://www.stat. berkeley.edu/ $\sim$ stark/bio.htm.

\section{Timothy "Tim" Stryker}

Timothy Stryker is Director of the U.S. Group on Earth Observations (USGEO) program, which supports the cabinetlevel National Science and Technology Council (NSTC) under the White House Office of Science and Technology Policy. Working with the USGEO Subcommittee of the NSTC's Committee on Environment, Natural Resources, and Sustainability, the program supports coordination of civil Earth observation activities, including systems assessments and data management initiatives, among multiple Federal agencies and their international partners.

Mr. Stryker's previous positions include Chief of Policy, Plans, and Analysis for the Land Remote Sensing Program of the U.S. Geological Survey; Executive Officer of the international Committee on Earth Observation Satellites; and Deputy Director of the Office of Policy at the National Reconnaissance Office. He has also served in assignments at the National Oceanic and Atmospheric Administration, the U.S. Department of Commerce, the Office of Management and Budget, the Federal Communications Commission, and the U.S. Information Agency.

A former Presidential Management Fellow, Mr. Stryker earned his master's degree in foreign service from Georgetown University and his bachelor's degree in history from the University of Michigan.

\section{Larry Sugarbaker}

Larry Sugarbaker is the National Geospatial Program Senior Advisor for the U.S. Geological Survey (USGS). Larry works on National Map policy formulation and new initiatives. He has led major studies to understand customer requirements for The National Map and for a national enhanced elevation program. Prior to joining the USGS in 2007, Larry was the vice president and chief information officer for NatureServe, an international nonprofit conservation organization. $\mathrm{Mr}$. Sugarbaker worked for the State of Washington, Department of Natural Resources for 22 years, where he managed the geographic information system and supported remote sensing, and forest inventory functions. He has gained worldwide recognition as a leader and expert in geographic information systems. Larry is a past chair of the National Research Council, Mapping Science Committee. He graduated from the University of Michigan, School of Natural Resources, with a B.S. degree in forestry in 1977. Larry completed an M.S. degree in remote sensing and wildlife management from the University of Michigan in 1979.

\section{Camille Touton}

Camille Touton is Counselor to the Assistant Secretary for Water \& Science at the Department of the Interior, Government Relations. Since August 2013, she has been senior policy advisor for water and power to ranking member Peter DeFazio, U.S. House of Representatives, Natural resources committee. She graduated from the University of Nevada Las Vegas in 2006, and attended George Mason University School of Public Policy during 2012-14.

\section{Bridgette Wessels}

Bridgette Wessels is director of the Centre of Interdisciplinary Research in Socio-digital Worlds (IRiS) and 
senior lecturer in sociology at Sheffield University, U.K. Her research focuses on the innovation and use of digital services including the development of public sector e-services and the development of e-Government and telehealth services. Her projects include the following: European Commission's Advanced TransEuropean Telematics for Community Help (ATTACH) project; the Engineering and Physical Sciences Research Council (EPSRC)-funded project Advanced Multi Agency Service Environments (AMASE), which addressed the development of new e-services and in particular focused on the design and takeup of advanced information and communications technology (ICT) in multi-agency health and social care services. She undertook a "Process Evaluation of National E-Government," funded by the Office of Deputy Prime Minister (U.K.) that addressed the implementation of innovative e-Government services. She has undertaken research that looked at the development and sustainability of portal e-services involving e@syconnects, (South Yorkshire), London Connects, and Digital City Ronneby (Sweden)(KTOF-HEIF 2 project). She has been involved in policy making innovative e-services through sitting on the South Yorkshire Digital policy group between 2004 and 2012. She has experience in the implementation of innovative e-services through her time on the e@syconnects (https://joinup.ec.europa.eu/community/epractice/case/ esyconnects) management board (2002-13).

She also has experience in the emerging field of open data and currently leads WP1 in the FP7 project, Policy RECommendations for Open Access to Research Data in Europe (RECODE). She is on the University Strategy Group on data management and open access. She has been expert for E.U., the U.K. Office of Science and Technology, Department of Trade and Industry, Royal Society, and European Parliament. Current projects focus on mainstreaming and implementing telehealth (Economic and Social Research Council and Technology Strategy Board [ESRC-TSB]); and a participatory design and co-production project on improving search and data management in research methodology (Arts and Humanities Research Council [AHRC]). She is evaluating the ESRC's National Digital Social Research Methods Programme, which covers a range of innovative projects that sought to understand how to use data including open data in research, which includes research in services and community settings. Her books have addressed many aspects of the innovation and development of e-services, for example "Inside the digital revolution: Policing and changing communication with the public" (Wessels, 2007), "The cultural dynamics of the innovation of new media: A case of telematics" (Wessels, 2010a), "Information and joining up services: The case of an information guide for parents of disabled children" (Wessels and Bagnall, 2002), "Understanding the Internet: A sociocultural perspective" (Wessels, 2010b), and "Exploring social change: Process and context" (Wessels, 2014).

\section{Sally Wyatt}

Sally Wyatt originally studied economics at McGill University, Canada (B.A., 1976) and Sussex University, England (M.A., 1979). She received her Ph.D. in science and technology studies from Maastricht University in 1998. Sally has more than 30 years of experience in teaching and research about technology policy and about the relationship between technological and social change, focusing particularly on issues of social exclusion and inequality. She worked at the Universities of Sussex (1980-86), Brighton (1988-90), East London (1990-99) and Amsterdam (1999-2006), as well as at the British Economic and Social Research Council (ESRC) (1986-88). Since 2006, Sally has been working for the Royal Netherlands Academy of Arts \& Sciences (KNAW), and since 2011, she has been the Program Leader of the KNAW's eHumanities Group.

Sally has played a central role in the international Science and Technology Studies (STS) community in different capacities. She was the international coordinator for the European Master's Programme on Society, Science and Technology (ESST) during 1996-99 and its president during 2008-11. She was president of the European Association for the Study of Science and Technology (EASST) during 2001-2004. Since 2011, Sally has been the director of the Netherlands Graduate Research School for Science, Technology and Modern Culture (WTMC).

Sally has received major research grants from the U.K. Economic and Social Research Council and the Canadian Social Science and Humanities Research Council. She has acted as an adviser to the European Commission's Science in Society program, as well as to several national European research councils interested in establishing and (or) evaluating social science research about new information and communication technologies. Her most recent book is an edited collection titled, "Virtual Knowledge. Experimenting in the Humanities and the Social Science," co-edited with Paul Wouters, Anne Beaulieu, and Andrea Scharnhorst (Wouthers and others, 2013). 


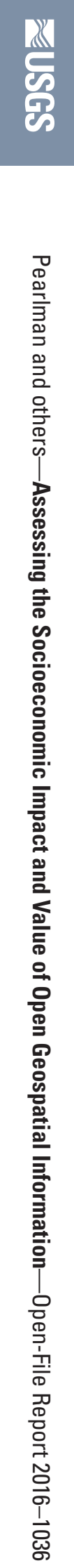